University of Rhode Island

DigitalCommons@URI

Open Access Dissertations

1992

\title{
The Clinical Psychologist Practitioner: Job Autonomy and Burnout
}

Ellen Lee Kenner

University of Rhode Island

Follow this and additional works at: https://digitalcommons.uri.edu/oa_diss

\section{Recommended Citation}

Kenner, Ellen Lee, "The Clinical Psychologist Practitioner: Job Autonomy and Burnout" (1992). Open Access Dissertations. Paper 1020.

https://digitalcommons.uri.edu/oa_diss/1020

This Dissertation is brought to you for free and open access by DigitalCommons@URI. It has been accepted for inclusion in Open Access Dissertations by an authorized administrator of DigitalCommons@URI. For more information, please contact digitalcommons-group@uri.edu. 
THE CLINICAL PSYCHOLOGIST PRACTITIONER:

JOB AUTONOMY AND BURNOUT

BY

ELLEN LEE KENNER

A DISSERTATION SUBMITTED IN PARTIAL FULFILLMENT OF THE REQUIREMENTS FOR THE DEGREE OF DOCTOR OF PHILOSOPHY

IN

PSYCHOLOGY

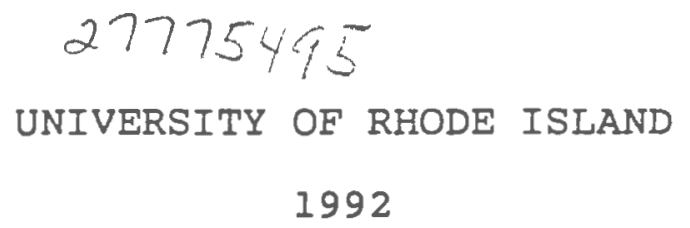


Copyright 1992

by

Kenner, Ellen L.

All Rights Reserved 


\section{ABSTRACT}

The survey study was conducted among psychologists licensed in the state of R.I. $(N=79)$. This study takes a sympathetic look at the provider. The goal is not to learn how to better control or manage psychologists, but to assess their well-being in the face of system-wide changes. Regression analyses are used to increase understanding of the relationship between psychologists job autonomy and burnout. Findings suggest that the degree of job autonomy is predictive of two subscales of burnout as assessed by the Maslach Human Services Survey, namely Emotional Exhaustion and Depersonalization. Additional items, including qualitative responses, suggest that autonomy is highly valued by psychologists.

Provider attitudes toward recent or proposed system-wide political and organizational changes are also assessed along with their preferences regarding certain practice dimensions (e.g., pay options, setting preference). Most providers prefer a private practice setting and. a fee for service payment method. Interestingly, provider attitudes toward "cost containment" issues did not correlate with any survey variables such as job autonomy, job satisfaction and the burnout subscales. This suggests that their attitudes toward controls were not generally predictive of behavior or experiences. Responses to questions regarding autonomy and government involvement 
in the psychologists practice seemed to vary according to the focus of the question. When questions focused on job autonomy directly, providers tended to dislike government involvement. When questions were addressed from a political level, e.g., asking about National Health Insurance, providers responses were more varied, however; the majority still disagreed with this policy. Qualitative responses to survey items lend additional support to the importance psychologists in this study place on job autonomy in their clinical practice.

This study has implications for psychologists, for administrators and for policymakers. 


\section{ACKNOWLEDGMENTS}

It is such a pleasure to express my gratitude to those who have helped me with this study and who have been there to offer me not only guidance and suggestions but emotional encouragement. I can proudly say that I did not burnout during this project and I plan to continue my studies in this area.

I want to thank my husband, Harris, for his unwavering and loving support, his good-natured humor and his natural interest in raising our chlldren together. He has a contagious benevolent outlook on life. On a minor note, I appreciate his letting me take over his office during the past two years, progressively moving him into a corner and even allowing me to share half of his desk, in addition to my own desk. I suspect the end to his good-naturedness regarding his desk might be close at hand since this study is nearing completion.

I would like to express a special thanks to Dr. Allan Berman for his enthusiastic encouragement in my pursuing this topic, in his helpful suggestions and in his careful editing of this study. More broadly and more importantly, I appreciate his kind guidance and frlendship over the past several years. He has been a strong source of support through my graduate years. 
My thanks to Dr. Charles Collyer who generously spent hours assisting me in methodology. His wise guidance was much welcomed as was his helpful suggestions regarding preparation of this paper. I respect his scholarship and his interest in philosophical ideas.

My sincere appreciation goes to Dr. Larry Grebstein for his interest in this topic; this has served as a source of support and encouragement. My thanks to Dr. Susan Trostle and Dr. Robert MacMillan for their willingness to review my study and to participate on my committee.

I am also appreciative of the efforts of several individuals who assisted me in the development of the survey. My special thanks to Dr. Edwin A. Locke who previewed my proposal and offered suggestions. I have learned much from his writings on the topics of job satisfaction and goal setting and highly respect him as a person, as a scholar and as a thinker. several professionals dedicated the time to preview my survey and offer helpful suggestions; I want to express my gratitude to Dr. Richard Greco, Dr. Bruce werber and Dr. Aderemi Dosunmu. And I am grateful to Joyce Langlais and Raymond Boornazian of Graphic Press whose professional expertise helped me produce a well formatted survey. My thanks goes to Robin Schuhmann who did an excellent job of preparing the malling list and assisting in sending out the surveys 
in a timely and thorough manner.

And this study would not have been possible were it not for the psychologists who volunteered their time to participate. I thank them, not only for completing the survey, but for their additional written comments which enrich this study. 


\section{PREFACE}

The standard Plan format was used in this dissertation. The gender references alternate between male and female in an effort to conform to common practice used today by APA style yet wanting to avoid the awkwardness of using the him or her double pronoun style.

The Maslach Burnout Inventory is not included in this study due to copyright legal protection but is available from Consulting Psychologists Press. 


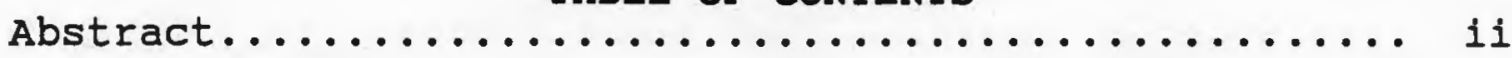

Acknowledgments $\ldots \ldots \ldots \ldots \ldots \ldots \ldots \ldots \ldots \ldots \ldots$ iv

Preface...................................

Chapter 1. Introduction.................... I

Background of the Problem..................... 2

Statement of the Problem................. 6

Research Questions................. 8

Additional Analyses................. 8

Purpose of the study.................... 9

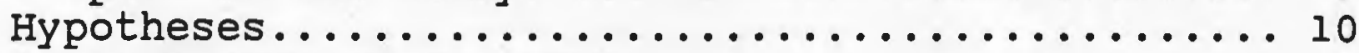

significance of the study.................13

Chapter 2. Autonomy and Burnout............. 15

Research on Autonomy and Job Satisfaction....... 15

Literature on Autonomy \& Job Satisfaction... 15

Litchenstein's Review of Earlier Studies.... 24

Recent Studies Job Autonomy \& Satisfaction.. 30 Autonomy and Legislation:

Definition \& Assumption............ 35

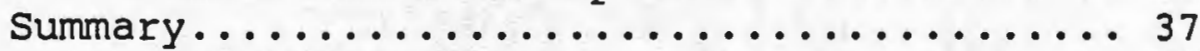

Description and Research on Burnout.......... 38

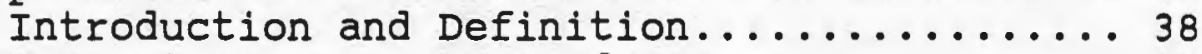

Burnout as a Unique Syndrome............ 39

Burnout Theory: Stages of Burnout........40

Burnout-Contributing Factors:

Characteristics of Individuals.......44

Characteristics of organizations......448

Summary....................... 51

Prevention of Burnout............... 52

Personal and Organizational Strategies

for Coping with Burnout.......... 52

Research on Job Retention............. 56

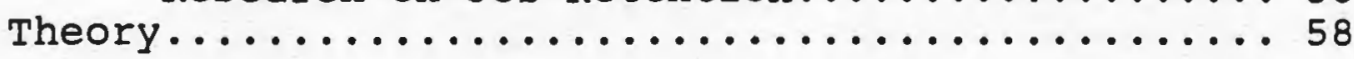

Chapter 3. Method........................64 64

Subjects..........................64

Measurements.........................64 64

Development and Design of Survey........664

Question and Response Formats..........6. 66

Internal Consistency...............66 68

Provider Autonomy...............69 69

Burnout....................69 69

Job satisfaction.................69 69

Attitudes toward Control Policies.....66 69

Additional Questions.............. 70

Maslach Human Services Survey.......... 70

Information on the MBI.............. 71 


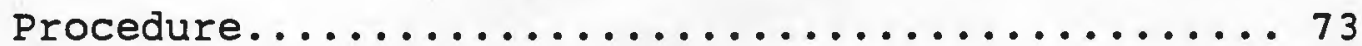

Conditioning Matrices............... 75

Handling of Missing Data.......... 75

outliers.................... 77

Skewness.................... 77

Chapter 4. Results and Discussion.............78

Survey Response..................... 78

Descriptive statistics................. 79

Demographic Information................. 80

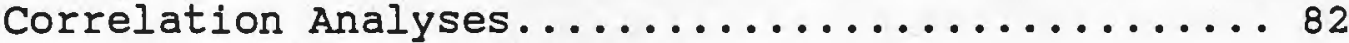

Correlation of Job Autonomy

with Burnout Subscales............. 83

Correlation of Demographics

with Burnout Subscales............ 83

Correlation of Job Autonomy

with setting Size............... 83

Correlations with Job Satisfaction....... 83

Insignificant Correlations............ 84

Intercorrelations of Burnout Scales....... 85

Importance of Autonomy................. 85

Statistical Analysis of the Hypothesis........ 87

Regression Analyses................ 89

Hypothesis 1

Autonomy \& Emotional Exhaustion.... 89

Hypothes is 2

Autonomy \& Personal Accomplishment.. 92

Hypothes is 3

Autonomy \& Depersonalization.......99 95

Factor Analyses.................. 98

Hypothesis 4

Central \& Demographic Variables.....998

Hypothesis 5

Central Variables...............101

Chapter 5: Additional Results of the Survey.........104 Psychologists Choosing to Leave the Profession....105

Provider Preferences and Attitudes...........108

Qualitative Data.....................116

Qualitative Item 1 :

Influence on direction of practice......117

Qualitative Item 2: Setting preference......119

Qualitative Item 3: Payment preference......122

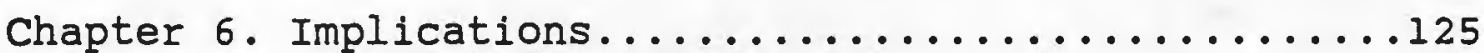

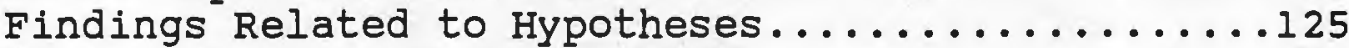

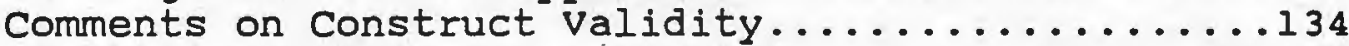

Limitations of the Current study............135

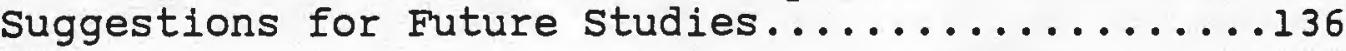

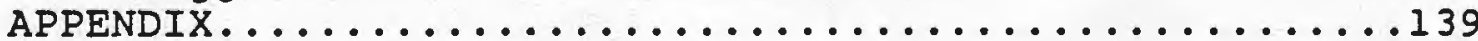

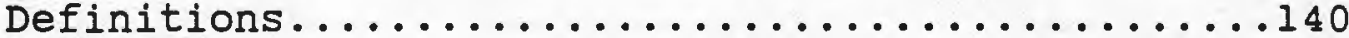

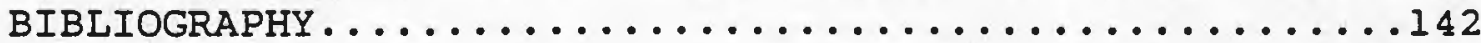




\section{LIST OF TABLES}

Table 1: Internal Consistency: Cronbach's Alpha Coefficients for Scaled Variables and Sample Items......................... 68

Table 2: Basic Demographic Information of Sample .... 80

Table 3: Intercorrelations of the Four Criteria and the Three Subscale Measures of Burnout...... 82

Table 4: Importance of Autonomy...............86

Table 5: Standardized Multiple Regression Coefficients as Predictors of Emotional Exhaustion Subscale of MBI............................ 90

Table 6: Standardized Multiple Regression Coefficients as Predictors of Personal Accomplishment Subscale (MBI)....................... 93

Table 7: Standardized Multiple Regression Coefficients as Predictors of Depersonalization Subscale of MBI......................... 96

Table 8: Component Measures, Rotated Factor Loadings, Communalities and Factor SSL's............99

Table 9: Component Measures, Rotated Factor Loadings, Communalities and Factor SSL's...........102

Table 10: Reasons for Considering Leaving

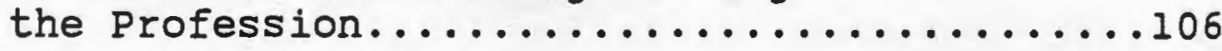

Table 11: Provider Preferences Regarding setting Type

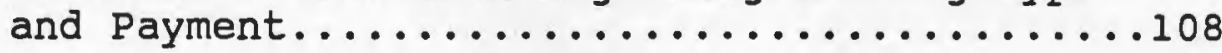

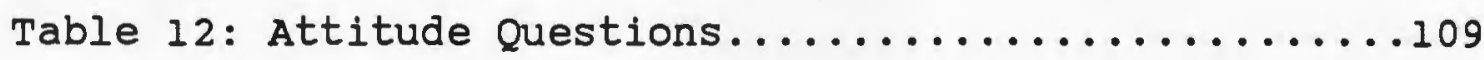

Table 13: Percent of Psychologists Finding Controls

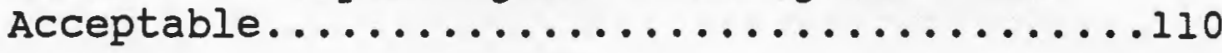

Table 14: Reimbursement Question...............112

Table 15: Preference \& Attitude Questions (Personal)...113 Table 16: Preference \& Attitude Questions (Vaiue).....114 Table 17: List of Responses to Qualitative Item 2....121 Table 18: List of Responses to Qualitative Item 3....124 


\section{LIST OF FIGURES}

Figure 1: Hypothesized Relationships between Job Autonomy Job Satisfaction and Demographic Variables........ 12

Figure 2: General Adaptation Syndrome........... 42 


\section{CHAPTER ONE}

INTRODUCTION

With rapid changes in health care delivery (from private practice to managed health care and government financed health care such as Medicare), providers are faced with a multitude of new factors such as cost containment, peer review, third party payers, risk management, cost shifting, quality assurance, diagnostic related group classification system -DRG's and more.

This shift in health care systems, from independent practice to increasing government control of health care (e.g., through regulation, legislation, tax funding) reflects a shift in values and in organization of health care. How is this shift in health care systems affecting the provider?

Studies done in the medical community show that increased bureaucratization leads to decreased autonomy and decreased job satisfaction (Licthenstein, 1984; Schulz, Scheckler, Girard \& Barker, 1990). The present study is concerned with the relationship between provider autonomy and burnout among licensed psychologists. 


\section{Background of the Problem}

Until recently, psychologists in the United states functioned with a high degree of autonomy. Most practitioners functioned in an independent practice model. Changes are occurring and are reflected in the literature: "Signs of metamorphosis are the decreases in solo fee-for-service practice as doctors increasingly join group practices...HMOs, IPAs...PPOS (Ku and Fisher, 1990, p. 26). what effect do the current trends have on the private practitioner? Is private practice soon to become obsolete?

Articles are appearing more frequently in psychology journals addressing this issue directly. In April 1990, the American Psychologist published an article "Is Solo Practice Really Dead?". The author, Moldawsky, argued no, that private practice is not dead. His comment was based on a random sample of licensed psychologists in New Jersey in which $87 \%$ of the respondents reported that they were in private practice. In The Family Therapy Networker (Nov/Dec 1990, p. 55), Stern wrote an article entitled "The Future of Private Practice". Stern quoted one private practitioner who fears the loss of autonomy: "I'm afraid that I'm going to lose my personal freedom, and the joy will be taken from my work. This is the best job I ever had and I don't want to lose it".

Listening to a panel of private practitioners at the 1990 Annual APA Conference, one heard concern about private 
practice and learned of a means by which some practitioners are trying to remain in private practice: they developed the "Group Independent Practitioner Model" to ward off the growing trend of managed health care and government controlled health care (McGihon, Kuebbing, A. A. Adams, M. A. Adams, Foster, \& Briddell, 1990). Moldawsky's conclusion that private practice is not dead might be true at this point in time, but whether private practice is in a process of dying is more of an issue.

Some are convinced that private practice is "terminally ill". Stern (1990) quotes former APA President, Nicholas Cummings as predicting that by 1995 private practice would represent only $5 \%$ of psychotherapeutic practice; with the loss of private practice goes "independence and financial security".

Managed health care models have continued to proliferate as regulatory incentives (e.g., Medicare, HMO legislation, employer requirements) have encouraged payers and providers to choose these alternatives (Brown, 1987, pp. 1-3; Michaels, 1987, pp. 50-548). From the pioneers at Kaiser-Permanente to the proliferation of Managed Health Care organizations: Health Maintenance Organizations (HMOs), Independent Practice Associations (IPAS), Preferred Provider Organizations (PPOS), Independent Practitioner Organizations (IPOS), Exclusive Provider Organizations (EPOs) to Capitated PPOs, Primary Care PPOS, "Swing-out HMOs and the many varieties of the HMO model (staff, 
group, captive group, independent group, network, and direct contact models) (Wagner, 1989, ch 2; spies, Friedland \& Fox, 1984, ch. 3). The provider gives up some autonomy to intermediary personnel, health service administrators (Lorentzen \& Roemer, 1988) and third party payers.

The prevailing ethical trends encouraging health care for all (e.g., World Health Organization, Dukakis" "Health Care for All" Plan for Massachusetts) are moving us even further from private practice towards more government, tax-funded health care (Toner, 1988). Legislative efforts, increased government rules and regulations, DRG's and Medicare expansions are now discussed more frequently by practitioners.

Kongstvedt (p. 1989, p.83) states that "Changing physician behavior is crucial to the success of any managed care plan." He cites physicians as unique with their "strong need for autonomy and control". If this is so, what might be one consequence of increasing government controls over health care providers? In a report on a national program, CBS This Morning (1990), a new trend was exposed - providers leaving the profession. One of the interviewed practitioners cited interference with patient care by third party insurers and government as reasons for leaving the profession.

Professional journals in psychology call for a "partnership between the private and public sectors" to 
serve difficult groups and define and measure quality of care (Simons, 1989). Additional articles in the American Psychologist argue similarly about the ethical role of government (B1ckman \& Dokeck1, 1989; Durenburger, 1989; Perkey, 1989). Health care rationing is no longer a forbidden term (Blank, 1988).

In this rapid web of changes, providers are faced with new responsibilities and roles. Utilization reviews, peer reviews, quality assurance and management, risk management and various other forms of data collection, e.g., physician practice monitors (Joseph, Devet, \& Dehn, 1986), all involve time and emotional effort that were not found in the traditional models. Routine reviews to third party payers or government in order to continue treatment, continual shifts in collection procedures, purposeful slowdowns in payment, procedural complexity, exotic terminology, fragmentation of transactions are some current trends that frustrate providers. Grumet (1989) has referred to some of the above trends as "health care rationing through inconvenience". "Defensive medicine", 1.e., giving the patient more than is required to protect against malpractice, is rising as is frustration from providers that some clients project an entitlement attitude (1.e., demanding a right to care, often for redundant, exaggerated or trivial complaints) that might run counter to the appropriate treatment (Ben-Sira, 1988; Cole, Haynes, Tierney, Tonkin \& Vawter, 1989). 
Interprofessional tensions are on the rise as a recent editorial in the American Journal of Psychotherapy (Leese, 1990) reveals: "Psychiatrists: "Don't look behind you! Someone may be catching up!" Providers from varying disciplines attempt to protect their practices by legislative means. Lobbying is on the rise in health care and providers are becoming involved in this political facet (Califano, 1986, p. 63; Buie, 1990). What are providers thoughts and reactions to the changes and what is the relationship between their current autonomy and degree of burnout?

\section{Statement of the Problem}

Research to be presented in Chapter 2 has demonstrated that job autonomy was found to be a strong predictor of work satisfaction, especially among highly trained intelligent professionals. In an extensive review on the nature and causes of job satisfaction, Locke (1976) states "previous research indicates that work satisfaction is engendered by work which is varied, allows autonomy, is not physically fatiguing, which is mentally challenging and yet allows the individual to experience success and is personally interesting" (p. 1342) [1talics added].

Lack of autonomy is also found to be a predictor of job burnout. Cherniss (1980) who studied burnout among 
publicly employed new professionals states "for most of the new professionals we interviewed, there was less autonomy and control and more routine and boredom in their jobs than they had expected, and interference from bureaucratic rules and actions occurred often enough to become one of the most disillusioning aspects of their jobs and a major cause of burnout." (p. 71) Maslach (1982) addresses the connection between burnout and autonomy as follows:

Burnout is high when people lack a sense of control over the care they are providing. This lack of control can stem from being told by superiors exactly what to do, when to do $1 t$, and how, with no leeway to do it differently (even when the old formula is not working in some new situation). It can be a consequence of having no direct input on policy decisions that affect one's job. It can arise when a person has no opportunity to get away from a stressful situation or is given more responsibility than he or she can handle. Whatever the reason for the lack of autonomy, not percelving control over important outcomes in one's job adds to the emotional strain of the helping relationship." (p. 40)

Psychologists have typically worked in traditional private practice settings without many outside controls. That situation has been changing over the past couple of years with increasing government and third party controls. Given the current changes in health care delivery, with more legislation, more administrative overlays, more rules and regulations, psychologists are bound to feel their job autonomy slipping away, even if they are still in private practice. Does this lessening of autonomy, as the literature suggests, predict job burnout? 
Since burnout is devastating both to the individual psychologist and to the delivery of quality care, and decreases in autonomy have been a strong predictor of burnout, there is an ongoing need to monitor providers autonomy and well-being in response to system-wide changes. Previously, much attention has been directed towards studying physicians; the current study focuses attention on psychologists with an additional focus on psychologists' attitudes towards outside controls.

\section{Research Questions}

The following questions have been addressed in this study:

First, how well does job autonomy predict burnout after controlling for possible confounding demographic variables (age of provider, gender, having offspring) among licensed practicing psychologists?

Second, what is the best combination of these variables in predicting burnout?

Third, given the autonomy variable and the above demographic variables, what are the most important variables contributing to burnout?

\section{Additional Analyses}

The next set of questions are assessed by factor analysis. 
First, are there any patterns of interrelationships among survey measures (Job autonomy, Job satisfaction, burnout subscales, attitudes towards controls, age and children)? If so, how do the variables cluster together?

Second, the five most central variables in this study were factor analyzed to assess their relatedness. These variables are job autonomy, job satisfaction and the three burnout subscales. The research question specifically asks whether burnout subscales, job satisfaction and job autonomy cluster together or on separate factors? Do they measure the same constructs or are they related but different?

Another research question asks what is the proportion of providers who have considered leaving the profession and what proportion of these name as their main reason increased controls, regulations and legislation?

\section{Purpose of the study}

The objective of the study is to explain whether the level of job autonomy (1.e., choice of patients, choice of treatment type, choice of treatment length and choice of reimbursement method) is related to the level of professional burnout. Based on theories mentioned below and previous research by Ben-Sira (1988), Burns, Andersen and Shortell (1990) and $\mathrm{Ku}$ and Fisher (1990), the hypothesis is 
that increased intervention (government or otherwise) over the provider has a detrimental effect on the provider in terms of burnout.

\section{Hypotheses}

The following hypotheses were tested:

Hypothes is 1

There is no linear relationship between job autonomy and burnout (Emotional Exhaustion subscale, EE), after controlling for age, gender and offspring among licensed practicing psychologists.

Additional analyses: what are the most important predictors of $\mathrm{EE}$ ? What is the best linear combination of IVs in the equation that predicts EE? How much total variance in EE is explained by the significant predictors? Which variables are not significant predictors of EE?

Hypothesis 2

There is no linear relationship between job autonomy and burnout (Personal Accomplishment subscale, PA), after controlling for age, gender and offspring among licensed practicing psychologists.

Additional analyses: what are the most important 
predictors of PA? What is the best linear combination of IVs in the equation that predicts PA? How much total variance in $P A$ is explained by the significant predictors? which variables are not significant predictors of PA?

\section{Hypothes is 3}

There is no linear relationship between job autonomy and burnout (Depersonalization subscale, DP), after controlling for age, gender and offspring among licensed practicing psychologists.

Additional analyses: what are the most important predictors of DP? What is the best linear combination of IVs in the equation that predicts DP? How much total variance in DP is explained by the significant predictors? Which variables are not significant predictors of DP?

\section{Hypothesis 4}

There is no pattern of interrelationship among eight survey variables: job autonomy, job satisfaction, attitudes towards controls, demographic characteristics (age and offspring) and the DV burnout subscales of Emotional Exhaustion, Personal Accomplishment and Depersonalization. 


\section{Hypothesis 5}

There is no pattern of interrelationship among the variables -job autonomy, job satisfaction and the burnout subscales: Emotional Exhaustion, Depersonalization, Personal Accomplishment.

Figure 1 summarizes the hypothesized relationships among variables which are based on research, literature and theories discussed in chapter two.

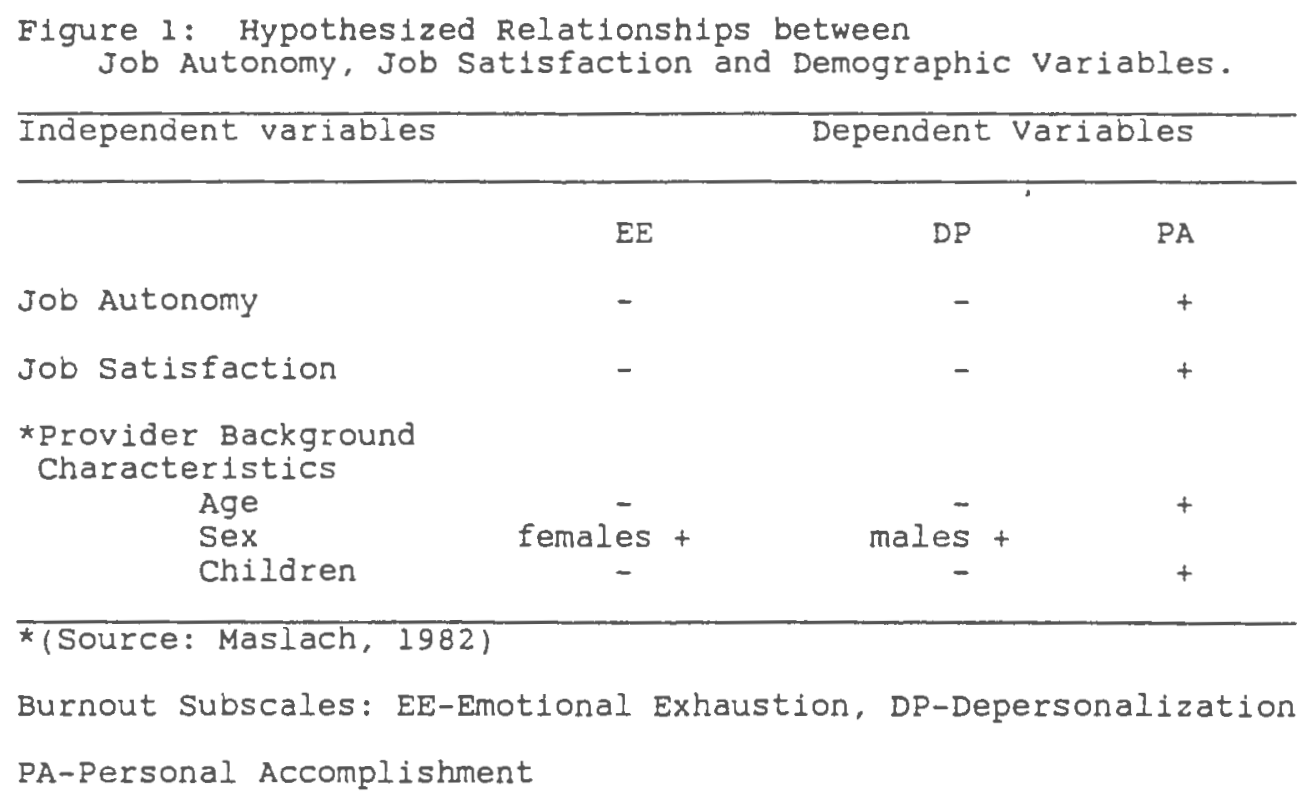




\section{Significance of the Study}

The aim of this study is to increase understanding of the degree of autonomy psychologists are currently experiencing, their attitudes towards controls and their level of Job burnout. Such an attidunal survey helps to examine current values and experiences of providers and offers a means of tracking attitudinal changes among providers over time. Hopefully, this type of study will help raise awareness of the effect of system-wide changes on provider well-being so as to prevent burnout. This type of study will also help us better understand what organizational factors contribute to provider satisfaction and high quality care, which will have implications for system-wide changes.

Many recent trends and suggested solutions to the health care "crisis" involve increasing controls over the clinical provider (e.g., review processes, third party payers, additional administrative record keeping, restrictions on length and type of treatment). This raises questions about how these controls affect the provider's mental health, the provider's job satisfaction and motivation, the provider's quality of care and the provider's future career outlook.

The value of the present study is that it combines a look at how job autonomy currently experienced by psychologists relates to job burnout; the research also 
assesses provider attitudes towards control strategies. To date, the researcher has found no studies that focus on this combination of variables for the clinical psychologist. The benefits of such a focus are to help psychologists become more aware of any relationship between job autonomy, attitudes towards controls and burnout. Increased awareness could lead to steps to prevent burnout and would have policy implications. Another benefit will be to increase our knowledge about the thinking and emotional well-being of individual psychologists - do they represent a homogeneous or heterogeneous group? It will serve as a source of information for providers, to help them reduce "pluralistic ignorance", i.e., feeling they are possibly alone in their experiences and attitudes (Colombotos and Kirchner, 1986, p. 183). Additionally, this study will add to the literature on burnout and to the literature about autonomy and controls across professions (e.g., studies done with physician populations). 


\section{CHAPTER TWO}

\section{AUTONOMY AND BURNOUT}

\section{Research on Autonomy and Job Satisfaction}

Research in the areas of provider autonomy, job satisfaction, burnout, bureaucratization of health services, and provider attitudes has steadily grown over the past several years, in part reflecting the major changes that have been occurring in the delivery of health care (Kongstvedt, 1989).

In psychology, as in other disciplines, much of the attention on the impact of recent changes is assessed by either focusing on client/patient satisfaction (Aday, 1989; Blue Cross \& Blue Shield Gallup Survey, 1990; Weiss \& Senf, 1990 ) or by studying provider response in order to control, manage or retain providers (Burns, Andersen, Shortell, 1990: Licthenstein, 1984).

\section{Iiterature on Autonomy and Job Satisfaction}

Provider autonomy with respect to system-wide changes has been extensively studied in the medical field; much less has been done in the mental health field. This is understandable since physicians were first affected by system-wide changes (e.g., Medicare in 1965).

Many researchers have focused on the effect of organization structure (e.g.. size of the organization, degree of bureaucratization) on physician autonomy and job 
satisfaction (Burns, Andersen \& Shortell, 1990; Engel, 1969; Udovch, 1983; Colombotos \& Kirchner, 1986; Ben-Sira, 1988; Schulz \& Schulz, 1988; Schulz, Scheckler, Girard \& Barker, 1990). In these studies there is some consensus that larger and more bureaucratized health care delivery arrangements, increasing controls (e.g., peer review, utilization review, a multitude of shifting payment arrangements, increasing paperwork) reduce provider's clinical autonomy, job satisfaction and hasten provider burnout.

The literature on physicians suggests that autonomy is an important variable. Schulz, Scheckler, Girard \& Barker (1990, P. 53) report from a survey study (N=545) that "most physiclans believed that their autonomy declined with the implementation of HMOs". The authors report that "By definition patient care that is managed by an organization suggests less clinical autonomy" (p. 44). The authors evaluate how the change from traditional private practice to an HMO affected practicing physicians. Looking at variables such as quality of care, earnings and autonomy, they found, in a three year follow-up survey, that "only with regard to the level of autonomy did most physicians report that HMO development had resulted in a change for the worse" (P. 51) with $63 \%$ reporting less autonomy $(\mathrm{N}=$ 288). The authors question whether over time, with more physicians switching to HMOs and less ability to shift costs to fee-for-service (FFS) customers, dissatisfaction 
might increase in other areas as well.

An interesting point made by the authors (schulz, Scheckler, Girard \& Barker, 1990, p. 53) is that the introduction of HMOs had a deleterious effect on those remaining with the traditional system (private practice, fee for service -FFS). Although interviews revealed that control procedures over physicians in HMOs were more rigorous, even physicians not joining an HMO felt the loss of autonomy. The authors presume this is partly due to limited referral patterns, being forced into discounted charges and anxieties about losing patients engendered by the HMO development; physiclans who did not join HMOs on average lost up to $1 / 3$ of their their caseload. It is not surprising that many physicians joined, in part, to retain patients.

The HMO development that these authors based their study on was not a voluntary, free market competing force but a government initiated change as the following illustrates:

Dane County wisconsin has experienced a dramatic transformation in its health services. On December 31, 1983, about 10 percent of the county population was in closed-panel HMOs. The next morning, on January 1, 1984, this proportion climbed to about 27 percent and by 1986 it had grown to over 40 percent. This change was precipitated by the state of wisconsin, which is the dominant employer in Dane county. In response to rising employee health insurance benefit costs, the state in 1982 announced that it was going to adopt direct provider bidding. The state offered to pay 105 percent of the lowest HMO premium bid or 95 percent of the standard FFS plan, whichever was lower. The new system required that state employees pay the difference if they did not 
accept the low bid plan. Fearful of losing patients to an older staff model plan or to newly emerging HMOs, 85 percent of physicians in Dane County either helped to form or joined one of five closed-panel HMOs, or associated themselves with a new open-panel plan. (p. 45)

Schulz et al. conclude that the change to HMO's in Dane County wisconsin has been a "major disruption" which "has resulted in the virtual elimination of independent solo or small group practices" most of whom "had to join or form large multispecialty groups or watch their patient base erode". They suggest that the "repercussions of the change from FFS to HMOs may be greater than the change itself" (p. 59). Loss of provider autonomy (e.g.. choices now made by HMO managers and HMO monitoring functions) was a major factor they identified as a consequence of this change in systems.

Schulz and Schulz (1988, p. 750) surveyed psychiatrists $(\mathrm{N}=144)$ in the Federal Republic of Germany. They found that "management practices in relationship to participative activities, supportive communication, and peer review activities were the most important predictors both of perceived clinical autonomy and work satisfaction". Also perceived clinical autonomy was an important determinant of work satisfaction. Contrary to other studies, the authors found that "psychiatrists in larger, less well funded, more managerially constrained, state institutions" had more perceived autonomy than those in "smaller, community general hospitals and private 
organizations". The authors suggest that perhaps some large organizations provide only a "general rule for medical care...to provide high quality care" leaving interpretation and implementation up to the individual doctor. Also, administrators in some large organizations might be so distracted timewise with bureaucratic administrative work that physicians end up with more independence. Integrating this with the fact that state controls and legislation have an impact not only on public practitioners but indirectly on private practitioners, it is possible that in this German state, the impact of state involvement might decrease the autonomy of private practitioners as compared to other countries, especially the United states, thus adding to a differential in perceived clinical autonomy. The findings in this one study were an exception to the review of many studies on this topic and lend to speculation about possible cultural differences or the specific job definition of these physicians (perhaps they play a big role in management and thus feel more autonomous even with more bureaucracy and less funding).

In an extensive review of a wide range of studies on physician satisfaction in different organizations (traditional private practice to varying degrees of organized bureaucracies), Licthenstein (1984, p. 139) focuses on the negative impact that bureaucratic organization has on job satisfaction of professionals and 
addresses the "theoretical question of whether professional job values and bureaucratic requirements are inherently in conflict". Interestingly, he finds, across many studies spanning across time (1961 to the late 1970's) and across countries (America, Israel, Britain) that "autonomy emerges as the hallmark of professionalism" (p. 140).

professionals, by definition, are trained to be knowledgeable experts in a specialized area; they have a high need for autonomy and self-regulation. Bucher and Stelling (1969, p. 13) state that the professional "derives his aims and methods from a professional body, works independently, and commands the privilege to autonomously determine what should be done and how it should be done".

This stands in sharp contrast to the concept of bureaucracies, "characterized by a hierarchical chain of command, clearly defined duties and obligations associated with each office, with goals and procedures determined at the top and conveyed down a chain of command - a type of system which would discourage autonomy and innovation among the ranks" (Bucher and Stelling, 1969, p. 13). Although Bucher and stelling argue that at the time of their writing (1969) professionals, such as physicians, exercised substantial control over the policies and operations of their organization. That situation is currently changing with the increasing the role of government in health care (Colombotos and Kirchner, 1986, p. 20).

Bucher and stelling continue, that "should a 
professional find himself operating within the confines of a formal organization, inevitable tensions and conflicts can be expected between the requirements of the bureaucratic system and the values of the professional." Cherniss (1980, pp. 58-59) states the conflict more forcefully:

Bureaucracy is perhaps the greatest enemy of professionalism. In several respects, the 'professional 1deal' and the 'bureaucratic 1deal' are completely incompatible. They represent two very different modes of organizing human action.

Cherniss elaborates that professionals have a collegial relationship and internal controls. Bureaucracies constitute an external form of control whereby "the organization infringes on one's autonomy and often does so in ways that seem to be harmful to one's clients". The author continues, "Many of those we interviewed gradually came to believe that it is simply impossible to provide effective, humane, and responsible service while adhering to the plethora of regulations and restrictions imposed by faceless and seemingly insensitive bureaucrats." (p. 59) Sarason (cited in Cherniss, 1980, p. 58) echos this theme: continued satisfaction is difficult "when daily reality confirms that you are not in control over your destiny, that decisions affecting your work and life are made elsewhere, often by people and forces unknown and unknowable to you." He continues, "the creeping sense of 
impotence, strange to professionalism however defined, has made professional work more problematic than ever."

Is increased organization always detrimental? In the examples discussed above, it is not primarily the degree of organization that is problematic, but the "separation of responsibility from knowledge". Locke \& Schweiger (1979) identify this common error as applied to organizations in general. The current author is applying this error to organizations in the medical field. Some highly organized settings are run by those having the most knowledge in the field (e.g., physicians remaining in charge of large group practice settings or hospitals). In such cases, those with the most knowledge about medicine, 1.e., the providers, are responsible for medical decisions and medical care. The authors (p. 326) refer to this type of leadership as "knowledge-based leadership". Ideally, such leadership is open to demonstrating the validity of decisions made and to giving rational explanations for such decisions; they are open to changing their decisions if they learn that they are in error. Locke and schweiger refer to this leadership type as authoritative, i.e., leadership that is knowledge-based and open to reason (as opposed to authoritarian).

other highly organized settings are run by or greatly influenced by those who are less knowledgeable about the service being provided (e.g., politicians making decisions regarding medicine). In such cases there is a separation of 
knowledge from responsibility. Those making decisions about medical care (e.g., politicians) have inferior knowledge about medicine. The less competent leaders can prevent the more competent providers from acting on their knowledge and judgement. When providers are forced to abide by decisions against their best judgement made by those less knowledgeable, the leadership style is characterized as "authoritarian" (Locke and Schweiger, 1979, p.326). Often this type of leadership is less amenable to reason and knowledge; rules and regulations are often arbitrary as clearly described in the examples presented above by Cherniss (1980) and Sarason (1977). Locke and Schweiger (1979) offer an excellent extended discussion on the managerial consequences of separating knowledge from responsibility.

Most studies confirm that there is a strong negative relationship between bureaucratic requirements of an organization and the autonomy and satisfaction of professionals. Licthenstein's review of some of the physician studies helps to increase understanding of factors associated with provider autonomy and satisfaction and will help guide the study of these factors in the field of psychology. Following this review is a review of some recent studies. 


\section{Litchenstein's Review of Earlier studies}

(Autonomy, Satisfaction, Bureaucratization)

Some early studies contrast heavily bureaucratized organizations with smaller less bureaucratized ones. There are some methodological problems in some of these earlier studies (e.g., small sample sizes, simple satisfaction measures) which are critiqued in Iichtenstein (1984). Even with his criticisms, Lichtenstein concludes "(that) the full-time, group physicians, the British GPs and the Israeli Sick Fund physicians were less satisfied than their comparison groups is undeniable" (p. 154). The comparison groups were the smaller, less bureaucratized groups. A description of some of these studies follows.

Mechanic (1972) did a comparison study of physicians in the British National Health Services, described as "very large, very organized, very bureaucratic health system in which patients pay on an almost totally prepaid basis" (Lichtenstein, 1984, p. 151) versus American group and non-group physicians. Strikingly. Mechanic found that doctors in the British National Health Service were substantially less satisfied with their practice than their American counterparts.

Physicians

British National Health Service American group \& non-group
Dissatisfied $\quad$ Satisfied

$49 \%$

$10 \%$

48

$53 \%$ 
British physicians complained of patient overutilization of services for trivial, unnecessary complaints. Mechanic cautions that the above figures were based on one question regarding satisfaction. However, he felt that the magnitude of the difference in response to this question cannot be dismissed.

Schulz and Schulz (1988), who also comment on Mechanic's study, note that United Kingdom GPs at the time of Mechanic's study, although subject to NHS contract and constraints such as very low income, did not practice in a physically large setting size but in independent solo or small group practices. The difference in magnitude of the response suggests that it is not size of the practice directly that affects satisfaction but perhaps the large bureaucratic organization (NHS) with the rules, regulation and hierarchical levels of authority that affect autonomy and satisfaction.

Much attention has been given to the nature of the organizations, not merely their size. As early as 1958, Ben-David (cited in Licthenstein, 1984, pp. 152-153; Engel, 1969 , p. 30) found that there are some large organizational models that facilitate the provider's work and do not inhibit provider's autonomy. He compared Israeli Sick Fund doctors to their Israeli counterparts in private practice (including large clinics) or on hospital staffs. This sick Fund is described as "nationwide (but private sector)... heavily bureaucratic, utilizing many rules, and employing 
structural arrangements and individual role definitions that made practice within it very different from private practice".

In the private practice categories, physicians generally felt that the organization enhanced their work. In contrast, Sick Fund physiclans were generally dissatisfied and alienated from their organization due to extensive administrative apparatus and arrangements with patients. Loss of autonomy was singled out as the foremost cause of physician dissatisfaction in the sick Fund. Complaints of this model were that patients overutilized the service due to unlimited access policies, patients made unreasonable demands and patients showed no respect for the physiclans. This was referred to as patient abuse of the system, 1.e., malingering. Additional complaints were that physicians had little control over referrals, worked in poor facilities, were to abide by an organizational assumption that there be no doctor-patient bond, and the responsibility for patient care rested with the organization, not the physician. Caution again is to be exercised in this early study due to the relatively low sample size $(\mathrm{N}=52)$. Many of the factors described above and in other earlier studies (e.g, "alienation") are ones that we now know contribute to "burnout" which will be discussed in a forthcoming section.

Friedson and Rhea (cited in Licthenstein 1984, p. 154) focused their attention on identifying different 
administrative/organizational variables that affect physician satisfaction, 1.e., the size, the extent of bureaucratization and financing policies. Physicians overall were satisfied. Their findings indicate that physicians in smaller, less bureaucratic groups and paid FFS (fee for service) were more satisfied with their autonomy and their relationships with patients than those in large size, heavily bureaucratized organizations with service contract policies.

Friedson and Rhea also note that these organizational variables explain their data better than do values held by the physician. Lichtenstein refers to this as the "dominance of organizational variables over individual attributes".

What are the main attributes of organizations that lead to physician dissatisfaction and lowered autonomy? In an article, "The Effect of Bureaucracy on the Professional Autonomy of the Physician", Engel (1969) concludes that those in highly bureaucratic settings are least likely to perceive themselves as autonomous. Her findings suggest that a moderate degree of organization is best.

Engel modifies Webers characteristics of bureaucracy (p. 31-32) to include components of bureaucracies which are potentially autonomy enhancing such as:

- access to unique/expensive equipment

- positive atmosphere of team/group work

- access to specialists within the group 
She continues to include components which are potentially autonomy restricting such as:

- numbers of hierarchical levels of authority with power centralized at the top

- high degree to which formally established system of rules and regulations exist and are used

Engel considered solo and small group practices to be nonbureaucratic; privately owned closed panel settings to be moderately bureaucratic; and government medical organizations to be highly bureaucratic.

Engel's findings indicate that a moderate level of organization ("moderate" referring to privately owned closed panel settings) is optimal for autonomy. On face value this finding seems to counter previous findings of the relationship between autonomy and bureaucracy. However, with her distinction of two aspects of bureaucracies: administrative characteristics which restrict autonomy and physical qualities of organized practice which actually enhance autonomy and the physicians ability to provide quality service, her findings make more sense. This helps us understand her point of why it is not size, per se, that limits autonomy, but the administrative bureaucratic structure of the organization.

In summary of Engel's study, it appears that the size of an organization is not a fundamental characteristic contributing to dissatisfaction or decreased autonomy. some large organizations enhance autonomy especially when 
offering means to provide better patient care (e.g., access to new technology or specialists, companionship of peers, research opportunities) whereas other large organizations thwart provider's autonomy and provider's goal of quality patient care (e.g., layers of administrative controls with rules and regulations). Engel suggests that bureaucracies are a varied mix to different degrees of both administrative controls and access to physical facilities (p. 34). Engel also identifies government ownership vs. private ownership as a main difference in these two groups. It was the moderately sized privately owned facility which the author found conducive to professional autonomy.

Licthenstein discusses a study by Demlo (1975) of physician satisfaction across several organizational types. The findings are consistent with previous findings by Mechanic, Ben-David, Friedson \& Rhea and Engel, namely, that large bureaucratic organizations or public employed physicians were most dissatisfied with their autonomy and their practice setting while physicians in small group, multispecialty and solo practice were markedly more satisfied with autonomy and practice setting.

Licthenstein (1984) sums up his review stating that physicians in solo or private practice are most satisfied while physicians in governmentally operated or prepaid models are least satisfied. The hallmark of professional job satisfaction that repeatedly appears as central across studies is autonomy. 
Recent Studies on Job Autonomy and Satisfaction

Burns, Andersen and Shortell (1990) studied the effect of hospital control strategies on physician satisfaction. In a survey study $(\mathrm{N}=616)$, they found that administrative responsiveness and provision of equipment and resources were rated lower in public hospital systems than in freestanding municipal hospitals. Looking at physician characteristics they found that work satisfaction increased with age and both work satisfaction and autonomy were positively associated with the number of years that physicians were working in a hospital system. Female physicians were found to have lower job satisfaction and less clinical autonomy. Interestingly, salaried physicians reported less conflict over autonomy and the authors suggested that this might be due to their adjusted expectations spelled out clearly in advance of taking their position, avoiding misunderstanding or conflict.

The suggestion that providers adjust their expectations or accommodate to negative situations was addressed in Litchenstein's review (1984) of a study by MCElrath (1961). MCElrath studied physicians in prepaid group practice. Providers who participated full-time in this prepaid group practice disliked many aspects about it (e.g., relationships with patients, pay and status) significantly more than providers with low participation in this model; relationships with colleagues was the only facet of work that satisfied high participators more than 
low participators. Oddly, despite their overall negative rating of practice factors, these high-participation providers sald they preferred group practice. McElrath (1961; cited in Licthenstein, 1984, p. 150) suggests a process of reconcillation to "necessary evils"; he suggests that providers adopt a "defensive perspective" to reconcile their dissatisfaction with continued participation in the prepald group practice. McElrath speculates that this defensive perspective might work by "restricting attention to group virtues while evaluating controversial features as 'necessary evils'". He adds, an ideological motivation (e.g., preferring groups) might also contribute to preference of this model.

Regarding provider's attitudes towards autonomy, Ku and Fisher (1990) analyzed physician attitudes of 23 "cost containment policies" (p. 38). Using factor analysis, the researchers reduced twenty-three policies to nine factors. of particular interest is Factor 2 which the authors conceptualized as placement of external controls on physicians' practice. Items in this factor focused on DRGs, government price controls for doctors' and hospitals.' fees and utilization reviews). Physiclans did not favor these external controls. Based on a 1984 national survey of 500 practicing physiclans $\mathrm{Ku}$ and Fisher found that the physicians generally disliked policies that decreased their autonomy in their practice. They raise the question that "If physicians become dissatisfied (with increasing 
controls). will they stop practicing or impede cost-containment practices now being used or developed? or will physiclans' attitudes change over time as they learn to accommodate the new systems" (p. 36).

$\mathrm{Ku}$ and Fisher wonder about the relationship between attitudes and behavior. Are attitudes generally predictive of behavior? To the current researcher, their study suggests that attitudes are not the sole determinants of behavior; there are other possible influences such as legal consequences, a person's decision to act on one's values, a person's ability or willingness to integrate and resolve the many conflicting "attitudes" many of us hold.

Indeed Colombotos and Kirchner (1986) found that legislation affects behavior but doesn't automatically affect attitudes, nor do the authors think it should. Quoting MacIver (1954: vii1), Colombotos and Kirchner (1986, p. 135) mention "No law should require men to change their attitudes.... In a democracy we do not punish a man because he is opposed to income taxes, or to free school education... but the laws of a democracy insist that he obey the laws that make provisions for these changes". However, Colombotos and Kirchner are aware that legislated changes can affect not only behaviors, but attitudes as well. An example of attitudes change is illustrated by AMAs resistance to the Medicare bill passed in June 1965. A boycott was called for with AMA expecting many physicians throughout the country to refuse to participate. By the 
following March, there were no longer any threats of a boycott (Colombotos and Kirchner, 1986, p. 140). As discussed earlier, could this be an example of "accommodation" to a "necessary evil"? This raises interesting ethical questions about government imposed or legislated change. Once a control becomes "legal" does that make it moral? When a provider has no legal means of redress, is there some process of silent conformity and appeasement; a compromising of their once held value of autonomy? What consequences might such a silencing have on these highly skilled professionals? Who benefits by such a silencing?

In their own research, Colombotos and Kirchner (1986) studied physicians "adaptation to change" prior to and after enactment of Medicare. They found that the initial resistance of such legislation conly $38 \%$ of private practitioners favored Medicare) shifted to $81 \%$ in favor only 6 months after passage of the legislation.

An exception to physicians accommodating to legislated change is the 1962 physician's strike against Saskatchewan, Canada's medical care plan. The authors offer an interesting discussion of this entire topic of autonomy, attitude change and legislation in their book, Physicians and Social Change (chapter 6 ) which is beyond the domain of this dissertation. Taylor (1990) has written a comprehensive history of the development of the Canadian National Health Insurance which also discusses the 
physician strikes. It is of interest that psychologists, rather than threatening to boycott Medicare legislation, actively fought to have such legislation passed.

More typically, providers have resisted any government or outside interference. Leyerle (1984, p. 75) notes that physicians have "fought every kind of government health care program and regulation, the creation of Blue Cross, and occupational health programs that showed any sign of impinging on their private practice." She continues that physicians use four primary means to resist external intervention over their practice. These four means are (a) opposing interventionist legislation, (b) lobbying for input into legislation, (c) attempting to head regulatory bodies mandated by legislation and (d) enforcing sanctions against alternative health care delivery programs. This brings us back to Licthenstein's question, guiding his literature review (1984), "of whether professional job values and bureaucratic requirements are inherently in conflict" (p. 139).

The current trends in health care delivery suggest that attempts to ward off government and third party interference in the delivery of health care services are losing ground and providers of health services are losing the autonomy that the profession had once enjoyed. The next section briefly discusses autonomy and ldentifies some of the legislative changes that have affected providers. 


\section{Autonomy and Legislation: Definition and Assumption}

Autonomy is defined in webster's Seventh New Collegiate Dictionary (1972) as "the quality or state of being self governing"; it is similarly defined in The New Webster's Dictionary (1990) as "self government". In the past, providers typically self governed and patients took personal responsibility for financially supporting or falling to support their own health needs. Decisions were made in a provider-client relationship. In the early to mid-1970's this "love affair (that) the American public had carried on with the medical profession for over fifty years" came under increasing attack from health care reformers (Leyerle, 1984, ch. 1, p. 4). In an article in HMO Practice $(1989$, p. 161), Schoenbaum and Plotkin acknowledge the fact that "Government plays multiple roles in today's health care, as it not only is a regulator of care, but often the largest single payer of care for a health care institution." [emphasis added]. The autonomy of the provider is thus affected.

An assumption in this research is that the mental health care delivery system is shifting from the traditional model of independent practice to either managed health care systems encouraged by increasing government legislation or to government health care as the following 1llustrates : 
Proliferation of State and Federal Regulatory Agencies

1916-18 Health insurance bills introduced in sixteen state legislatures; none is passed.

1920 American Medical Association passes resolution declaring opposition to "compulsory contributory insurance against illness"

1928-32 Committee on the Costs of Medical Care publishes 28 reports on health issues: final report recommends group practice and that the costs be covered on a prepayment basis, through the use of insurance, taxation, or both.

1935 Social Security Act (health insurance excluded for fear of endangering act as a whole)

1939-47 Health Insurance supported by president Truman

1945 Governor Earl warren introduces health insurance bill in California legislature; warren Bill is opposed by CMA and defeated.

1965 Medicare bill signed by president Johnson and President Truman in Independence, Missouri.

1966 Medicaid program operated by the states, receiving both federal and state tax funding to provide health services for the poor. It began as a fee-for-service program.

1972 Social Security Act Amendment establishing professional standards review organizations (PSROs), capital expenditure review, federal support for rate setting.

1973 Health Maintenance Organization (HMO) Act

1974 Health Planning and Resources Development Act establishing government health system agencies and requiring that states adopt "certificate of need" programs

1976 Amendments to HMO law encouraging medical school graduates to work in underserved areas.

1977 President Carter's hospital cost containment bill.

1981 Omnibus Budget Reconciliation Act that encourages states to adopt "gatekeeping" and managed care systems.

1982 Tax Equity and Fiscal Responsibility Act which introduces PRO's, asks Dept. of Health and Human Services to deliver "prospective payment plan" for Medicare payments to hospitals, liberalizes HMO Medicare payment methods, introduces Hospice benefits in Medicare.

1983 Congress adopts prospective payment system for hospitals.

1984 Child Health Assurance Program to Medicaid and Deficit Reduction Act imposes a temporary freeze on physician fees in Medicare.

1986 Consolidated Omribus Budget Reconciliation Act imposes new regulations on employers)

(adapted from Taylor, 1990, pp. 226-227; Brown, 1987, pp. 1-3; Additional source: Herrick, 1989, pp. 263-266) 
Serious thought is being given to increasing the role of exclusive government involvement (e.g.. rationing, licensing and regulating the profession, Medicare, Medicaid, Mission Commission plans for National Health Care). Califano (1986, p. 62) states that the "largest single customer of the health care industry is the federal government". Califano continues, "In 1984 uncle Sam paid about \$112 billion for health care - picking up bills for everything from Medicare and Medicaid ( $\$ 85$ billion) to vaccines for childhood immunization, rehabilitation, veterans' hospitals, care for the military and their dependents, and basic research at the National Institutes of Health in Bethesda, Maryland." With increasing government legislation and intervention, providers' options regarding their profession are narrowing.

\section{Summary}

These studies and others suggest that job autonomy is an important determinant of physician satisfaction and patient care. What is the emotional-psychological toll on providers whose autonomy is reduced? Burnout was chosen as variable to help assess any association. What follows is a description of burnout and a summary of some relevant research. 


\section{Research on Burnout}

\section{Introduction and Definttion}

The concept of burnout has received much attention over the past two decades. Burnout is a form of occupational stress found among providers in human care services (Udovch, 1983, p. 1). The term burnout originally meant "out of fuel", referring to a rocket's depletion of fuel (Mangano, 1982). It is now used to refer to health professionals running "out of fuel" due to the nature of their work (e.g., close emotional involvement in clients' lives), personal variables (e.g., setting unreasonably high expectations then trying to cover up stress with a calm facade) and organization variables (high bureaucratization with accompanying reduction of provider autonomy). Providers suffering from burnout tend to handle stress or emotional overstimulation in a similar way, that is, they become detached and indifferent or cynical toward clients (Udovch, 1983).

Mangano (1982, p. 5) defines burnout as "a depletion of physical and mental resources; a lack of energy and motivation that slowly erodes the spirit; a state in which feelings of frustration, futility, and cynicism replace 1dealism and purpose at a high cost to both employee and employer". Pines and Aronson (1988, p. 9) define burnout as "a state of physical, emotional, and mental exhaustion by long term involvement in situations that are emotionally 
demanding" and Freudenberger and Richelson (1980, p. 13) offers a similar definition.

\section{Burnout as a Unique Syndrome}

Freudenberger (Mangano, 1982) distinguishes burnout from stress, depression, nervous breakdown, workaholism and job dissatisfaction as discussed below. Symptoms of burnout include "a feeling of being 'drained' ...chronic sleeplessness, frequent, persistent colds, stomach disorders, and occasional disorientation...a feeling of Impotence (Mangano, 1982, p. 11). Freudenberger's distinctions are described below.

Burnout is a form of stress. It is the end of a spiral of job stress: a person feels stressed (e.g.. emotional overstimulated), fails to cope with the stress (e.g,. distances from clients), feels more stressed, again fails to cope and so on. After several turns on the spiral, the person gives into the emotional exhaustion and does not make attempts to cope with the stress.

Burnout differs from depression. A person who is burned out can leave work for the day and enjoy an afternoon of sailing. A depressed person has vegetative signs and symptoms chronically. Burnout remains somewhat somewhat confined to the job and a person might still enjoy other facets of his life once away from the job.

Burnout is not the same as an emotional breakdown. A psychotic break is accompanied by inability of a person to 
function with reality. Delusions, hallucination and strange behavior often accompanies such a break. A burned out person may feel incapable but this person still has job skills. Burnout is more an experience of "I don't want to work" rather than "I can't work".

Burnout is not the same as being a "workaholic" (Mangano, 1982). A workaholic often achieves goals and does not feel like a chronic failure; in burnout, one's efforts often end in frustration and one begins to feel like a fallure.

Although burnout is related to many of the above concepts (e.g., it can lead to depression), burnout as described in the literature has been limited to a specific type of experience - involving emotional exhaustion, depersonalization and decreased sense of personal accomplishment among helping professionals (e.g., nurses, psychologists, doctors, teachers).

\section{Burnout Theory: Stages of Burnout}

Burnout is considered to occur in gradual but recognizable stages which differ according to the providers feelings, problems and reactions. Below is a summary of the stages of burnout based on a description by psychologist Edelwich and described on a video by Mangano (1982) and in Edelwich's and Brodsky's book (1980, p. 42), Burnout. Here the term providers will be used since they are the subjects of the current research. 
Stage I Enthusiasm: "How can I do a good job?". This stage occurs when the provider sets high expectations of his job and himself. He fails to meet some of these idealized goals and tends to blames himself, not his expectations or the outside influences. Providers who are more susceptible to burnout are overly dependent on the job for feelings of self worth and happiness.

Stage II Stagnation: "What good is this job for me?" Expectations are not met (or with recent changes, the rules and regulations might have been manipulated and changed). The provider becomes disgruntled and cynical. He lowers expectations and feels somewhat powerless.

Stage III Frustration: "I'm a cog in a wheel." The provider falls to achieve goals after hard effort he becomes resentful of others and doesn't try to change anything; his career loses value and he is cynical about others' goals. The main symptoms are psychosomatic illnesses, 1rritability, exhaustion, possible addictive habits - preoccupation with food, drugs, alcohol. Frustration is partly due to job overload or job monotony. with recent trends, frustration might also be due to administrative controls and increasing and shifting rules and regulations (Grumet, 1989). 
Stage IV Apathy: "I just show up for work and go through the motions - I'm office deadwood". This stage is characterized by alienation and estrangement. At this point symptoms of clinical depression may occur with hopelessness spreading to other areas of one's life. This is the most dangerous stage of burnout - providers experience personal guilt and feel inadequate.

In summary, the stages of enthusiasm, stagnation, frustration and apathy help us understand burnout as a gradual process of emotional exhaustion stemming from both personal and work setting characteristics. Udovch (1983, pp. $25 \& 53$ ) notes a resemblance between Edelwich's stage model of burnout and Selye's (1974, p. 39; 1956, p. 87) general adaptation syndrome (GAS), also called the "biological stress syndrome". Selye hypothesized three stages of stress: the Alarm Stage, the Resistance Stage and the Exhaustion Stage (Figure 2).

Figure 2: General Adaptation Syndrome (GAS)

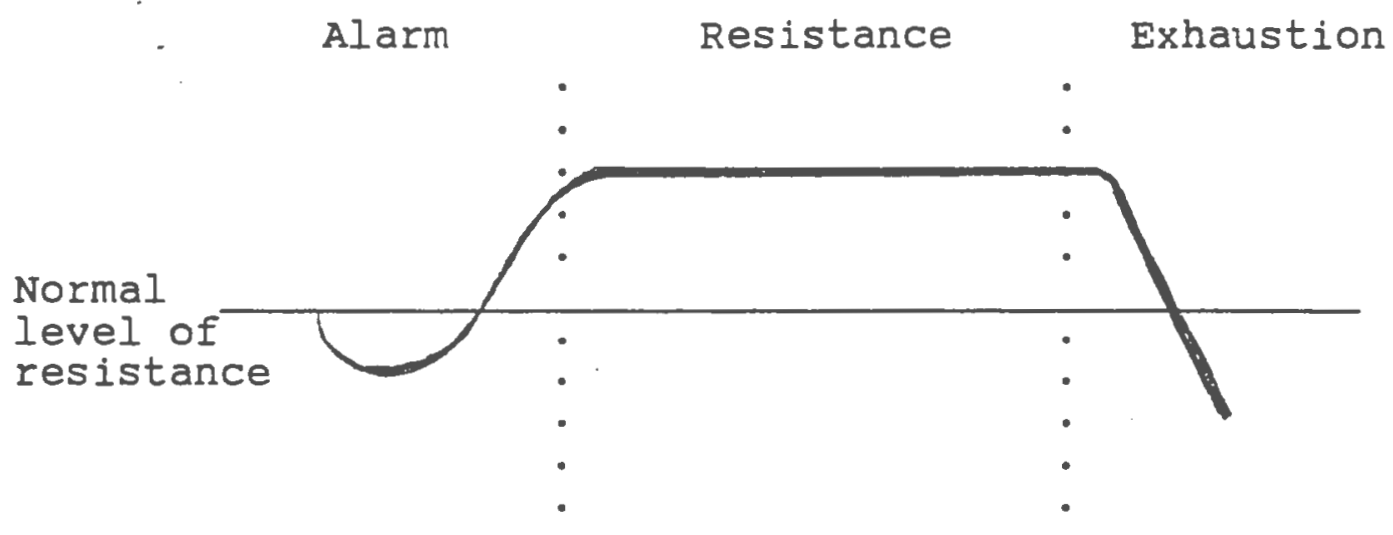


Udovch's (1983) insight into the similarity between these models of stress is described below.

In selye's alarm stage, one encounters a stressor. One responds with alarm, mobilizing one's energy. One's normal resistance is lowered by this response. This alarm stage resembles the enthusiasm stage of burnout: this occurs when an employee faces the positive and negative challenges and stressors of a new job with heightened expectations.

In Selye's resistance stage (arousal and appraisal), one is able to ward off the negative threat with constant effort. Udovch (1983) suggests this phase resembles the stagnation and frustration stages of burnout in that the individual is continually trying to adapt to chronic stress with sustained effort.

Finally in Selye's exhaustion stage, one is no longer able to sustain one's coping efforts. Under such prolonged chronic stress, one gives up exhausted and suffers both physical and psychological symptoms. Udovch notes that this resembles the apathy stage of burnout in which the individual gives in and suffers psychological and physical consequences (e.g., cardlovascular or gastrointestinal diseases). 


\section{Burnout}

\section{Contributing Factors: Characteristics of Individuals}

Costs of burnout are both personal and economic. Personal costs include low self esteem, poor health, listlessness, bitterness, feeling unmotivated and wasted talent. Economic costs include high turnover rate, absenteeism, demoralization of organizations, reduced effectiveness on the job and increased medical expenses.

what personal characteristics and organizational characteristics contribute to burnout? Unlike some other professions, psychologists' work involves serious emotional effort and involvement with one's clients, hence making psychologists more vulnerable then some other professions to burnout. The emotionally over-stimulating nature of psychotherapy and under stimulation of creative abilities (e.g., in some bureaucratically controlled settings) are contributing causes of burnout that psychologists might face. But how might psychologists and other "helping professionals" differ amongst themselves, causing one individual to be more susceptible to burnout than one's colleague?

An important personal characteristic mentioned by Edelwich and Brodsky (1980, pp. 52-60) is having unrealistic expectations. These unrealistic expectations pertain to oneself as a helper, to one's cllents, to one's capacity to be a change agent, to expectations of immediate and universal success, to one's expectations of client 
motivation, to expectations of client's appreciation, to expectations of further training and to expectations of a rewarding work environment. Expectations are also considered a factor in burnout (Freudenberger and Richelson, 1980). Other personal factors mentioned in Udovch include a high achiever personality and a lack of skills in measuring "success" on the job, leaving one feeling like a chronic fallure.

Heckman (1980, cited in Udovch, 1983) studied provider characteristics and found that those with a humanistic theoretical orientation were more prone to burnout then those with a cognitive-behavioral or psychoanalytic orientation. Heckman suspected that the emphasis on emotional involvement in the humanistic orientation makes one more susceptible to burnout. Regarding personality factors, Heckman found some factors that might make a person susceptible to burnout, but personality factors were not as strong as worksetting factors. Factors he discusses are psychotherapists who are more conventional, dependent, somewhat fearful of interpersonal involvement and often more preoccupied than their colleagues.

Gann (cited in Udovch, 1983, p. 9; cited in Maslach, 1982, ch. 4) studied provider characteristics of burnout. Her results suggest that personality characteristics making one susceptible to burnout are aggressiveness, passivity, low self-confidence and/or being interpersonally reserved. Maslach elaborates on these personality profiles which make 
one "bound for burnout" (Maslach, 1982, p. 62). She describes three categories of burnout prone individuals. The first category reflects an unassertive, anxious, submissive person who has difficulties setting limits; this individual will acquiesce to demands and is thus susceptible to burnout, especially emotional exhaustion. The second category describes an intolerant, impatient person who has difficulty with anger management and will project hostility onto clients. The third category describes a person who is conventional with little ambition and low self confidence. This person also yields to demands rather than confront challenges. These personality characteristics have been found to place one more at risk for burnout.

Demographic characteristics have been correlated with burnout. Maslach (1982) highlights several important variables. Age has been found to have a clear relationship with burnout (Maslach, 1982, pp. 59-60). Younger professionals are more prone to burnout. With increased age, Maslach suggests that chances of burnout diminish due to increased maturity, more stability and knowledge and a more balanced perspective on life; additionally, those who burnout when young are may leave the profession entirely, leaving the older group with fewer burnout prone individuals.

Marital status and family status (i.e., having children) also have shown a consistent relationship with 
burnout (Maslach 1982, pp. 60-61; Maslach \& Jackson, 1985). Single individuals are most susceptible to burnout, especially the emotional exhaustion component. Married individuals have been found to have the least amount of burnout; they are less prone to depersonalization and they experience an increased sense of personal accomplishment. Divorced individuals show a mixed picture: like single individuals, they tend to experience higher emotional exhaustion; like married individuals, they tend to be less prone to depersonalization and they experience an increased sense of personal accomplishment.

Not having children has been associated with a greater risk of burnout (Maslach, 1982). Individuals without children have been found to experience more emotional exhaustion and depersonalization and a lower sense of personal accomplishment. Maslach suggests that married individuals or those with children typically reflect an older, more stable population with more psychological maturity. In addition, rather than increasing emotional exhaustion, having a spouse and/or children might reflect additional sources of support, affection and outside interests (i.e., the job is less likely to become the sole source of satisfaction). Marriage and childrearing can give one increased experienced in dealing with interpersonal conflicts and problems. Maslach notes that being single and childless gives one more flexibility to leave a dissatisfying $j o b$ and less incentive to endure 
dissatisfaction.

Studies on gender differences with respect to burnout suggest that gender has only a small influence on burnout. There is some indication that women are more prone to experience burnout as emotional exhaustion, whereas men are more prone to experience burnout as depersonalization (Maslach, 1982, p.57). Maslach suggests that this may reflect socialization factors encouraging women to express emotions more readily and encouraging men to be more emotionally controlled, "big boys don't cry". In Maslach's and Jackson's more recent survey studies (1985) they find that men show slightly more burnout than women. Overall, Maslach \& Jackson (1985, p. 837) suggest that "sex of the employee is not a major factor in burnout".

The discussion above focused on individual characteristics and demographic variables that may make one more susceptible to burnout. The next section examines organizational characteristics contributing to burnout.

\section{Burnout}

Contributing Factors: Characteristics of organizations

Although personal characteristics have been identified, it has also been suggested that these are less important than the actual organizational characteristics. As mentioned earlier, Heckman (1980) found that personality characteristics were not as strong as organizational characteristics in predicting burnout. Friedson and Rhea 
(cited in Licthenstein, 1984, p. 154) also found that organizational variables explain their data better than individual attributes. They referred to this phenomenon as "the dominance of organizational variables over individual attributes".

This review of the literature (above) showed that organizational variables (e.g., the size and the degree of bureaucratization, affect provider autonomy. Researchers have also found that these organizational variables strongly affect burnout. Freudenberger (Mangano video, 1982) found that the quality of the work environment strongly affects chances of burnout. Relevant to the current study, he mentions that lack of autonomy and boredom are strongly associated with burnout.

Freudenberger describes a "bad" work situation (Mangano, 1982, pp. 72-73): employees have "vague job responsibilities which are changed everyday to suit someone else's whims....There is too much ambiguity, particularly when they try to make decisions of their own. They rarely get a chance to do so without consulting three or four people who are eager to put in their two cents to prove their own usefulness." He continues, "When a decision is made or a project completed, there is no feeling of support, no recognition or positive response from superiors. They view their peers as potential enemies rather then as a source of information, support and comfort." Freudenberger sums up: "Employees who believe 
it's useless to voice their concern will keep their resentment buried inside. They become robots, operating at minimal capacity." This is a description of characteristics of organizational settings that often lead to provider burnout.

In contrast, in "good" work environments, according to Freudenberger (Mangano, 1982, pp. 72-73) there is "more autonomy and less red tape. Meetings, reports and reviews are used to produce constructive results, and not to obstruct progress." He comments that there is a cooperative and friendly atmosphere with colleagues which produces positive results.

organizational setting problems are mentioned by Edelwich and Brodsky (cited in Udovch, 1982, p. 6):

1. Lack of support

2. Inadequate funding

3. Poor case management

4. Low pay

5. Large case load

6. Lack of upward mobility

7. Inadequate criteria to measure results

Cooper (cited in Udovch, 1983, p. 33) also tries to isolate sources of occupational stress and lists eight possible stressors:

1. Type of work

2. Nature of work environment

3. Nature of the work load

4. Clarity of the job (e.g., ambiguous)

5. Level of management and leadership skills

6 . Degree power or autonomy (e.g., lack of autonomy)

7. Quality of relationship with workers (e.g., poor relationships)

8. Opportunity for career development (e.g.. lack of career development) 
Udovch (1983) studied the interaction of worksetting and personality with respect to burnout. Her findings partially support Heckman's findings. Psychotherapists in institutional settings had more burnout than those in private practice with respect to a sense of personal accomplishment. Possible reasons suggested by Udovch ( $p$. 138) for this finding are lower pay found in the public sector, lack of institutional support by the public and lower support on behalf of administration for providers work with clients.

Relative to the current study, the research on burnout and the research on Job autonomy and job satisfaction offer converging evidence that autonomy and burnout are related. For example, degree of bureaucratization has an impact on both factors. Also, autonomy was found to be an important factor in decreasing stress-related 1llnesses such as migraines, ulcers and heart disease which are frequent symptoms of burnout. Burnout and lack of autonomy were found to be related to decreased work effectiveness. (Finch, 1976; Cooper, 1977, c1ted in Udovch 1983, p. 38)

\section{Summary}

In summary, several researchers have attempted to isolate organizational characteristics and individual characteristics that contribute to burnout on the job. There is some evidence that organizational characteristics exert more influence in causing burnout. Individual 
characteristics are thought to determine susceptibility to this syndrome. One observation from looking at the literature on Job autonomy, job satisfaction and burnout is that these variables are related. The current study focuses direct attention on this relationship.

Identifying contributing factors to burnout is one important step. Other researchers have worked to identify factors that help one cope with feelings of burnout. A short discussion of coping skills and recommendations for organizations follows.

\section{Prevention of Burnout}

\section{Personal and Organizational strategies}

\section{for Coping with Burnout}

Medelros and Prochaska (1988, p. 113) studied how psychotherapists successfully cope with stressful clients. Although their focus was on difficult client populations, not on difficult worksettings, their findings might be important in helping providers cope with burnout. Their results suggest six successful coping mechanisms: humor, self-reevaluation and wishful thinking ("a critical evaluation of one's feelings coupled with a passive attitude toward problems"), optimistic perseverance ("optimistic goal-directed behavior"), seeking inner peace (a tranquil state), seeking social support (information and direction) and contingency control or avoidance ("denying a 
thought, a fact or its implication or with altering the environment"). Individuals susceptible to burnout might benefit from learning coping skills.

Meichenbaum (1985, p. 10-11) acknowledges that stress reduction often has to be targeted at the organizational level, not just at the individual level. Organizational changes or Job redesign are often required to reduce stress.

Freudenberger (Mangano video, 1982) mentions several steps that can be taken to prevent burnout. These include changes administration can take to improve working conditions. He mentions task rotation, limiting overtime, providing regular breaks, hiring extra staff when needed, modifying workloads, providing adequate Job preparation, providing enrichment programs and training seminars for staff, providing meetings to help resolve interpersonal conflicts, providing regular but informal feedback, periodically reviewing organization goals and employee's responsibilities and offering in-house counseling by an outsider.

Udovch (1983) discusses several means to prevent burnout as developed over the years by Freudenberger (1974), Edelwich and Brodsky (1980), Steiner (1980), warnath and Shelton (1976) and Maslach (1976) as follows:

Changes in Personal Characteristics - Providers can learn about the limitations of the agencles they work for and have a good understanding of the clientele so as to avoid unrealistic 
expectations.

- Providers can learn to focus on success cases or follow up on clients who make progress. A focus on small changes in clients helps providers identify success rather than expecting major changes in unrealistic time frames.

- Providers should not assume that they are responsible for creating the client's problems, and remember that it is the client's responsibility for making changes.

- Providers benefit from regular exercise.

- Providers benefit from relaxation techniques.

- Providers benefit from proper eating habits.

- Providers benefit from sharing feelings with colleagues regarding cases and burnout.

- Providers benefit from involvement in professional organizations.

Changes in the work environment

- Improve training procedures for professionals, with

a focus on encouraging flexibility in approaching tasks rather than a narrow role definition.

- Have staff maintain some sort of direct client contact to remind staff/administrators of the realities of the provider-client relationship.

- Include clinical practice experience in training programs experiences so as to avoid unrealistic expectations.

Freudenberger's suggestions (1975):

- Rotating assignments.

- Limiting and staggering hours.

- Creative time off schedules (taking sick time when not sick).

- Professional development time (e.g., seminars, workshops) with freedom to implement some of the knowledge gained at these sessions when back on the job.

- Careful selection of worksetting and colleagues with whom to associate. (Boy \& Pine, 1980, cited in Udovch) Maslach's suggestions (1976):

- Regular vacation schedules.

- Lower client-provider ratio.

- Time-out from stressful situations.

- Less direct client contact. (Occasionally rotating jobs to less stressful situations.)

Pines and Aronson (1988, p. 149) suggest a cognitive approach to decreasing burnout. They mention keeping a log of "daily stresses, coping strategles, and success or failure in coping", clarifying priorities and setting 
realistic goals.

Some researchers have even tried to measure "mental work load" as an important factor accounting for provider stress and consequent provider performance (Betram, Hershey, Opila \& Quirin, 1990, p. 458). The authors view mental work load as "an important variable intervening between work demands imposed on physicians and physician performance". They look at six dimensions of mental work load: "performance, time load, mental effort, physical effort, psychologic stress, and difficulty". Mental work load was found to be "inversely associated with physician satisfaction, with the patient care they provided and with their self-rating of the quality of care they provided".

Heckman's findings (1980, mentioned in Udovch, 1983) suggest that psychologists who work in institutional settings suffered from burnout more often than those in private practice (both solo and group practice). This finding supports similar findings on organizational settings in the area of job satisfaction and autonomy.

In summary, researchers have been working to identify both individual and organizational characteristics that are associated with burnout. They have also developed individual and organizational strategies to help prevent burnout. 


\section{Research on Job Retention}

Lichtenstein (1984) reviews some large studies that have been done to examine the relationship between provider autonomy, satisfaction, organizational structure and burnout from the vantage point of figuring out how to retain physicians on the job.

Issues of job autonomy and job satisfaction relate to burnout and burnout affects job retention, 1.e., turnover rates. A primary goal of successful health care organizations is that they have stability and predictability over their staff. Given the knowledge that autonomy is one of the most important determinants of job satisfaction and burnout, what alternatives do health care organizations have to encourage physician retention?

One means is to set up organizations which are essentially provider determined (Madison, Tilson and Konrad. 1977). Another solution is to do away with highly bureaucratized organizations which restrict autonomy and to encourage solo, small group or moderate sized organizations which are set up to enhance autonomy. A third alternative suggested by Licthenstein (1984, p. 167) is to pre-select physicians with "certain psychological needs or job values" that make them more prone to long tenures in large bureaucratic organizations. These studies are focused on how to retaln providers.

In a study by Prybil (cited in Licthenstein, $1984 \mathrm{p}$. 170), the author mentions frequencies of reasons cited for 
wanting to leave a large organization. The most frequently mentioned reasons were as follows:

$\begin{array}{ll}\text { Dissatisfaction with pay } & 48 \% \\ \text { Autonomy matters } & 39 \% \\ \text { "too much supervision or control" } & 37 \% \\ \text { Lack of control over work load \& hours } & 27 \% \\ \text { Poor patient-physician relations } & 24 \%\end{array}$

The importance of autonomy and control are reflected in these responses.

Ross (1969 cited in Licthenstein) studied variables that were associated with turnover rates. Ross found that turnover rates of physicians in group practices increased as centralization of management increased; he also found that turnover rates of groups decreased with increased group size. Ross found that $60 \%$ of those leaving group practice went into solo or small group practice; only $8 \%$ went into military or public practices.

In summary, the problem that these studies address is how to retain physicians. If one can't offer them autonomy, then one can seek providers who value autonomy less. Alternately, one can return to traditionally smaller private practice settings. Finally, one can find means to "motivate" or force providers to stay in large institutions, to serve particular populations and to accept certain fees. Legislation and political mandates have been used to this end (Taylor, 1990). These studies look at physician satisfaction, job autonomy and burnout from an administration problem solving perspective. 
The research revlewed above has focused on provider well-being from various vantage points - from the vantage point of the importance of provider autonomy to job satisfaction, from the vantage point of identifying correlates of burnout and burnout prevention and from an administrative vantage point of how to retain physicians on the job. The next section looks at theoretical frameworks for understanding Job autonomy, job satisfaction and the role of increasing organizational controls on these factors.

\section{Theory}

Theorists and researchers in industrial-organizational and social psychology have proposed theorles that would support the hypothesis that increased controls lead to decreased motivation, productivity and autonomy. An interesting cultural difference also exists reflecting different underlying values across cultures.

In his textbook, Psychology Applied to work (1983 \& 1987, pp. 394-395), Muchinsky refers to the cultural basis in job satisfaction. In the United States, Muchinsky says, "we value individual freedom, personal growth, and 'opportunity'. Such values stem from formal documents like the Bill of Rights...from the bellef that America is the 'land of opportunity', as attested to by the millions who 
emigrated from their native countries for a chance at a new life..." The author goes on to contrast our values with those in Russia. There are over 3,000 articles on Job satisfaction but Muchinsky says "I know of only one Russian study on job satisfaction... In the Russian culture, feelings about work are not important."

Below are some of the theories from the fields of industrial organizational psychology and social psychology. Adam's equity theory (1963) suggests that we have a means to internally monitor the justice of an exchange. If we judge the ratio of our efforts to equal the financial and nonfinancial rewards, then we feel the system is just; when our efforts do not feel equitably compensated, we experience a state of "undercompensation inequity". We try to increase our rewards or decrease our input in an attempt to equilibrate the situation. Conversely, if we feel we are given too much for our efforts, "overcompensation Inequity", we tend to increase our output or decrease our compensation. Studies indicate that inequity is associated with a high turnover rate and that salaried employees modify both the quality and quantity of their work when they experience inequity (Muchinsky, 1987, ch. 10).

Locke's goal setting theory (Locke \& Latham, 1984, p. 6 ) suggests that our motivation to achieve goals depends on our conscious decision to pursue such goals. Locke and Latham state "since individuals possess free will (volition), it is not inevitable that every individual will 
set goals. People have a choice in this regard - not only with respect to whether they set goals, but also as to the types of goals they will set (number, complexity, time span), the process by which they will set them, and their integration with other organizational practices". Our active participation in setting goals and our acceptance of goals increases our motivation and willingness to work for goals according to this theory.

Locke addresses the effect of regulation on motivation and goal setting as follows:

"...the economy can take unpredictable turns as a result both of past government regulation and present decisions of the President and congress. These can affect the rate of inflation, interest rates, and consumer demand, all of which influence the feasibility of strategic goals. Government regulations affect business in numerous ways. The government routinely tells business people:

...where they can build (zoning), whom and how to hire (EEOC), how much to pay (EEOC and minimum wage laws), how to design the work environment (OSHA), what hours the employees can work at a given pay rate (overtime laws), when they can be open (blue laws), what prices they can charge and how successful they can be in terms of growth (antitrust laws and price controls)... how to negotiate with unions (Labor Department and NLRB), what insects and fish can be destroyed in the course of doing business (ecology laws), what products they can sell and who can perform what jobs (licensing laws), what amount of profit they can keep (IRS), what they can say to stockholders (SEC)...and this only scratches the surface. A given firm may have to deal with government agencies at four different levels [and even multiple jurisdictions within the same level]: municipal, county, state and federal, and the various regulations may even contradict each other, be changed and applied retroactively, be uninterpretable, be 
totally arbitrary and cost millions of dollars to implement and hundreds of thousands to protest." (Locke, 1984, pp. 151-152)

Relating to providers, increased legislation and regulation add layers of work onto providers that were minimal or non-existent in the fee for service (FFS) model. As one illustration of increasing government control over providers, the tenth bill introduced into the House of Representatives in 1991 called for "legislation mandating physician acceptance of assignment of specific or all medical procedures as a condition participation in the federal Medicare reimbursement program (91-H-5010 R.I. introduced by Representatives Cardente, Murphy, Heffner, Remington, Dailey and Metts). The current trends seem to support increased government control over providers. Locke's theory has been supported by research (Muchinsky, 1987, p. 485); 1t emphasizes the role of active personal participation and intention in goal setting on increasing work motivation and satisfaction.

Reinforcement theory suggests that positively reinforced behaviors are more likely to occur again. For example, monetary rewards have been found to increase job productivity and job performance when pay is perceived as equitable and directly tied to performance (Muchinsky, 1987, ch. 10).

Expectancy theory by Porter and Lawler suggests that we are more highly motivated when we expect a successful task accomplishment, when we anticipate intrinsic and 
extrinsic rewards, and when we value and desire such rewards. This theory has been useful in predicting job satisfaction and job effort (Muchinsky, 1987, ch. 10).

The ability to set challenging, specific goals, feeling justly compensated for one's effort, recelving positive "reinforcement", expecting successful task accomplishment and rewards (both intrinsic and extrinsic) are all elements involved in work satisfaction and work motivation.

Work motivation is defined in an American Psychologist article on this topic (Katzell \& Thompson, 1990, p. 144) as "a broad construct pertaining to the conditions and processes that account for the arousal, direction, magnitude, and maintenance of effort in a person's job". The work environment for clinical psychologists has been rapidly changing over the past few years and it is important to monitor the impact of these changes on provider autonomy, job satisfaction and provider burnout as it applies to clinical psychology.

Ben-Sira (1988), who has studied the effects of political involvement in the Israeli medical system, warns of the effects of politically engendered entitlement attitudes, consumer/provider dissatisfaction, and the potential for using the "medical care" issue for consolidation and misuse of political power. Describing the Labor sick fund he says: 
...Labor fund physicians are less likely than others to demonstrate affective behavior, and to legitimize presentation of somatoform disorders. They feel more than others burdened by excessive visits and redundant complaints, evidently a subjective interpretation of their reluctance to legitimize somatoform disorders. Their perception of being burdened with excessive patient load and being exposed to redundant visits... is greatly affected by their view of (1) the system creating a sense of entitledness that encourages overutilization, and (ii) the system (latently) professes the attainment of non-medical interests. (p. 151)

In summary, theorists and researchers suggest that the degree of control that one has over one's livelihood (e.g., in terms of goal setting, reimbursement, intrinsic and extrinsic rewards) affects one's satisfaction and motivation. We are in a state of transition in the mode of health care delivery and in the ideas supporting these trends; it is of value to directly assess what effect current trends are having on the provider. 
CHAPTER THREE

METHOD

Subjects

The subjects were psychologists who were licensed by the state of R.I. in 1990. This list sample was obtained from the Rhode Island Psychological Association. Local practitioners are the focus of the study; hence retired members, those practicing in distant states and those practicing less than 8 hours a week were excluded. The inclusion criteria for this licensed psychologist list were 2 years of clinical training and having passed the oral and written exams in clinical psychology (only one provider noted being grandfathered into this list). The addresses on the list are the "preferred addresses" that the psychologist gave the R.I. Department of Health.

\section{Measurements}

\section{Development and Design of Survey}

An analysis of prior instruments relating to health care surveys and a review of the literature on formulating questions and formatting questionnalres (Aday, 1989; $\mathrm{Ku} \&$ Fischer, 1990; Ben-Sira, 1988; Rutman, 1984; Jones, 1985) was done to help in the development of the survey. Cholce of survey questions regarding the degree of 
external controls (provider autonomy measure) and demographic information was influenced by and guided by several sources which include a questionnaire by Ben-Sira (1988) on physician satisfaction with different systems of health care in Israel, Ku's and Fisher's Questionnaire on Cost-Containment Policles (1990), the Rand Corporation's and John Ware's Mental Health Index (McDowell \& Newell, 1987, pp. 133-138), a Physictan Survey by Burns, Andersen and Shortell (1990), the Georgia Psychological Association Survey of Managed Mental Health Programs (Gardner, Adams, Sherman, Rainer, 1990), several representative samples of surveys presented in Aday's book, Designing and conducting Health Surveys (1989) and McDowell's and Newell's book, Measuring Health: A guide to rating scales and questionnaires (1987). Questions concerning current trends in health care and on attitude toward self were developed from relevant literature and references already cited for degree of external control measure above.

The survey was reviewed by several providers at a preliminary stage. The providers completed the survey and gave written and/or oral feedback. They were asked to screen the survey for any ambiguous or poorly worded questions. Eight providers from several fields (e.g., Medicine, Dentistry, Industrial Psychology, Podiatry) offered constructive comments. These surveys were not part of the final sample. The goal was to highlight any ambiguous or poorly worded questions and to get general 
impressions. Revision and refinement of the survey was guided by feedback given.

\section{Question and Response Formats:}

Likert-type scales were used for most items (e.g., to measure provider autonomy, Job satisfaction, attitudes concerning controls, value questions, desire to leave the profession).

Clinical autonomy was specified on the survey as composed of freedom to choose in four main job related areas with a Likert response format ranging from no choice to total choice.

1) Clients in caseload

2) Fees

3) Type of treatment

4) Length of Treatment (number of visits)

The survey was comprised of several groups of questions which addressed current job satisfaction, importance of autonomy, perceived autonomy at work, attitudes toward suggested control policies, value attitudes, questions relating to worksetting and pay options, burnout and demographics.

The demographic information gathered by the survey focused on the provider's individual characteristics. Demographic information used in the main analyses are described as follows: 
Provider age is a categorical measure with a response format as follows:
1) below 25
2) $26-30$
4) $41-50$
3) $31-40$
5) $51-60$
6) $60+$

Provider sex is a dichotomous measure: 1)male 2) female.

Children (whether or not the provider have offspring) is measured by a dichotomous variable, 0) no 1) yes.

Questions pertaining to worksetting focused on setting size, setting type, setting preference and preferred pay options. Worksetting variables used in the main analyses are described below. Setting size is described using categorical variables, each denoting a progressively larger setting size:

$$
\begin{aligned}
& 1=\text { solo practice, } \quad 4=\text { medium group }(6-15) \\
& 2=\text { partnership, }
\end{aligned}
$$

Pay options are described using a dumny variable coding:

1 = annual salary

2 = fixed annual amount for each patient

3 = fixed fee for each service

4 = own customary fee for each service FFS

5 = capitation (set amount of money based on

6 = other membership)

7 = annual salary and FFS. 


\section{Internal Consistency}

Cronbach's alpha was used to assess internal consistency of scales. The results are displayed in Table 1.

Table 1

Internal consistency

Cronbach's Alpha Coefficients for Scaled Variables

\& Sample Items $\left(\mathrm{N}^{-}=79\right)$

\begin{tabular}{|c|c|c|}
\hline Scale & ha coef & Sample item \\
\hline Provider Autonomy & .72 & $\begin{array}{l}\text { In your clinical practice, to what } \\
\text { what degree do you feel you have } \\
\text { some choice (i.e., autonomy) over } \\
\text { the following issues: } \\
\text { a. Clients in your caseload. }\end{array}$ \\
\hline \multicolumn{3}{|l|}{ Burnout } \\
\hline $\begin{array}{l}\text { Emotional } \\
\text { Exhaustion }\end{array}$ & $\star(.96)$ & $\begin{array}{l}\star \star \text { I feel like I'm at the end } \\
\text { of my rope. }\end{array}$ \\
\hline $\begin{array}{l}\text { Personal } \\
\text { Accomplishment }\end{array}$ & $\star(.71)$ & $\begin{array}{l}\star \star \text { I feel I'm positively } \\
\text { influencing other people's } \\
\text { lives through my work. }\end{array}$ \\
\hline Depersonalization & $*(.79)$ & $\begin{array}{l}\text { * } \text { I feel I treat some } \\
\text { recipients as though they } \\
\text { were impersonal objects. }\end{array}$ \\
\hline Job Satisfaction & .73 & $\begin{array}{l}\text { How happy, satisfied or pleased } \\
\text { have you been with your clinical } \\
\text { practice during the past month? }\end{array}$ \\
\hline Controls & .72 & $\begin{array}{l}\text { Establish government price controls } \\
\text { for clinical psychologists. }\end{array}$ \\
\hline \multicolumn{3}{|c|}{$\begin{array}{l}\text { b } \\
\text { * Numbers in parentheses are alpha coefficients from Maslach and } \\
\text { Jackson data (1981); N=1316. Reprinted in Udovch, } 1983, \mathrm{p} .82 \text {. } \\
\text { * Permission to print these samples items given by Jili Troy, } \\
\text { Permissions specialist with Consulting Psychologists Press. }\end{array}$} \\
\hline
\end{tabular}


Provider Autonomy. The survey asked providers about their current autonomy on their clinical job. Current professional autonomy was measured by responses to four items (alpha $=.72$ ) asking about clients, type of treatment, length of treatment and fee.

Burnout. The three subscales of burnout were assessed separately. Emotional Exhaustion (EE; 9 1tems) subscale had an alpha of .86. Personal Accomplishment subscale (PA; 8 items) had an alpha of .64 . Depersonalization subscale (DP; 5 items) had an alpha of .66 . It is noteworthy that were one item to be removed from this later subscale the alpha would improve to .80 . The outlying 1tem (\#22) asked if providers felt their clients accused them of causing their problems (paraphrased for copyright protection).

Job Satisfaction. Providers were asked about current job satisfaction, a measure that is used as a construct validity check with burnout. This measure had three items with an alpha of .73 .

Attitudes toward Control Policies. Providers were asked about their attitudes toward control policies (e.g., nationalizing mental health care, rationing services). These attitudes were assessed by a series of nine 1tems $($ alpha $=.72)$. 
Additional questions. Some questions asked providers about ethical/political attitudes; other areas questioned reflected personal preferences for health care. Frequency information on these questions can be found in chapter 5 .

\section{Maslach Human Services Survey}

Burnout was measured by the Maslach Human Services Inventory (alternately called the Maslach Burnout Inventory, MBI). The MBI consists of three subscales which were each assessed as separate DVs in the model. The three burnout subscales are Emotional Exhaustion (EE), Personal Accomplishment (PA) and Depersonalization (DP). The MBI is a 22 item instrument that measures these three subscales of burnout in a reliable manner. Sample items from the MBI are listed in Table 1 above.

The MBI has been extensively used across various subjects. Subjects used in scale development include the following: psychologists, physicians, social workers, nurses, police and spouses, agency administrators, teachers, counselors, probation officers and attorneys (Maslach \& Jackson, 1986, p. 30). Subjects respond to each Item on a seven-point Likert scale of current frequency of experience $(0=$ never; $3=a$ few times a month; 6 = every day).

Permission to use the MBI was obtained from Jill Troy, Permissions Specialist with Consulting Psychologists Press. The investigator purchased the right to reproduce and 
modify 400 copies of the Maslach Burnout Inventory with minor modifications approved in the contract. Modifications included an easier to read format (small boxes to check off Likert categories), simplified instructions, reduced size, reprinted with the rest of the survey in booklet form and substitution of the word "client" for "recipient", since this term is used more frequently in the psychological community. Agreement was also made that the MBI would not be reproduced in this dissertation except for sample items specified by the publisher.

\section{Information on the Maslach Burnout Inventory}

According to the Tenth Mental Measurements Yearbook (Conoley \& Kramer, 1989, p. 476) this instrument "appears to be a well-researched instrument of an important construct". The review continues that the Maslach Burnout Inventory (MBI) is "certainly the instrument of choice to use in research and evaluation endeavors studying the phenomenon of burnout". This instrument was systematically developed over a perlod of 8 years by the "leading experts" in the field. Burnout refers to job and personal variables that interfere with work performance and satisfaction. The 22 question survey asks about ones feelings and attitude towards work. Respondents score each question by the frequency of occurrence on a scale of 0 (never)- 6 (almost always). The inventory provides raw summative scores for 
each of the three subscales: Emotional Exhaustion, Depersonalization and Personal Accomplishment. Questions for each subscale are independent of questions on other subscales. A profile and ranking of burnout is given on these scales.

Reliability and validity data are good. For reliability, two studies on test-retest (2-4 weeks) gave coefficients ranging from $.60-.82$ and from $.54-.60$ after 2 years. Convergent and discriminate validity are supported and reported in the manual. The overall standardization sample consisted of 11,067 individuals (mental health workers, social service workers, medical workers, teachers, postsecondary educators, attorneys, police officers, ministers, librarians, and agency administrators. The occupational subgroup of interest in this study is mental health workers (psychologists, psychotherapists, hospital staff mental health workers, counselors, psychiatrists (N $=730)$.

The MBI is negatively correlated with the Job Satisfaction Inventory. The researchers feel that the construct of burnout might be related to, but not the same as, the construct of clinical depression; more research is needed in this area. The researchers also mention that the Maslach Burnout Inventory subscales were not significantly correlated with the Crowne-Marlowe Social Desirability (SD) Scale at the .05 level (Maslach \& Jackson, 1986). 


\section{Procedure}

During the week of July 8, 1991, a "warm contact" postcard was sent to providers letting them know of the upcoming survey (Aday, 1989, p. 200). On July 19, 1991 the surveys were sent out to 257 providers. The survey packet included a cover letter explaining the nature of the survey, a consent form for research, the 7 page survey and a request form for a summary of the survey. Two weeks later, August 1, 1991, a follow-up postcard was sent out as a reminder to subjects asking them to complete and return the survey if they had not already done so. All information was anonymous. No coding or any other method of 1dentifying the participants was used. Precautions were taken to ensure that the principle investigator was blind to knowledge of who was in the study. For example, surveys were given to the primary investigator only after having been removed from envelopes with return addresses; requests for summary information of the study upon completion of this study were detached from surveys and were followed up by someone other than the principal investigator.

Data from the surveys was checked for outliers, missing data, multicollinearity and singularity, normality, linearity and homoscedasticity of residuals. Descriptive statistics were done on most survey variables. These statistics include the mean, standard deviation, frequency graphs, skewness, kurtosis and range. Tabulations of 
subscale scores for MBI was done by using the Lotus 123 computer software.

Internal consistency reliability (correlations between answers to different questions about the same concept) was assessed by Cronbach's alpha coefficient. Cronbach's alpha coefficients were done on several measures (MBI subscales, satisfaction questions, autonomy scale, control measure).

Content validity was addressed by basing survey items on current topics in the literature, using variables and questions similar to items used in previous studies or in pre-existing surveys as discussed below. Several providers from different fields (e.g., dentistry, podiatry, pediatrics, organizational psychology, general medicine) participated in a preliminary critique of the survey to help ensure that questions being asked adequately represented the concepts of interest and that survey questions were clear and straightfoward.

Multiple regression analyses were done to indicate which set of variables contributed most to prediction of the DV (direction and strength). The relative contribution of each independent variable was also assessed. Provider burnout subscales (i.e., Emotional Exhaustion, Depersonalization, Personal Accomplishment) were assessed in separate multiple regression analyses since the MBI manual states that there is not yet enough evidence to Justify a composite burnout score. The data were analyzed using two statistical software packages, SAS (Schlotzhauer 
\& Littell, 1987) and SPSSX (Norusis, 1988); LOTUS 123 was also used.

\section{Conditioning Matrices}

Handling of Missing Data. Among the surveys, there was surprisingly little missing data. All respondents $(N=79)$ answered all items on satisfaction questions, current professional autonomy and current setting size. Below is a list by variable category of the amount of missing data and how it was handled.

On the importance of autonomy and preferred pay option, one item was missing from the total $(N=79)$. This item was imputed by using the median across subjects.

On the Maslach Burnout Inventory, only five of the total 1738 items were missing (.3\%). They were randomly distributed and the five were imputed by using the average respondent's score on the appropriate subscale (within subjects).

on questions pertaining to attitude toward controls, ten of 869 items were missing $(1 \%)$ and there was no pattern among the missing units. Median values across subjects were used to impute these items.

On questions pertaining to preferences or moral attitudes, seven of a total of 790 items were missing (.8\%). These were imputed by using the median across subjects.

Even items more typically vulnerable to missing data, 
e.g. household income, were surprisingly complete. Five units of 79 were left incomplete $(6 \%)$ and were imputed by central tendency across subjects (mean, median and mode all had a value of 6 ). Hours of clinical work a week had two missing units filled in with the median across subjects. Only in one area was there significant missing data and this pertained to questions asking the average number of hours per month of government related paperwork required for payment ( $N=63 ; 80 \%$ answered), the average lag time between services offered and government-related reimbursement ( $\mathrm{N}=51 ; 65 \%$ answered) and reimbursement for time spent responding to reviews (from third party payers or government) $(\mathrm{N}=69 ; 87 \%$ answered $)$. One respondent's written comments stated that their bookkeeper kept track of this billing information; the provider did not monitor this information. This could be one explanation for the reduced number of responses on these three questions. Descriptive statistics are given for these three questions; these statistics are based on the actual number of responses (i.e., no missing data were imputed). 
outliers. Univariate box plots and bivariate scattergrams were checked for univariate and bivariate outliers. Five outliers were identified and handled by moving the scores to the nearest (lowest) category. This maintains their same ordinal position, preserving the deviancy of the score, but not allowing one score to unduely affect the correlation (Tabachnick \& Fidell, 1983, p.76). Two outliers were 1dentified in the measure on the importance of autonomy, two outliers identified in Depersonalization and one outlier identified in current autonomy. There was no pattern among the outliers.

skewness. Caution was taken to test assumptions of normality. All major variables, with one exception, had a $z$ score for skewness less than the cutoff designated by Tabachnick and Fidell (1983, p. 79) of + or -2.58 . The $z$ score on Depersonalization exceeded this cutoff. This violation of normality was subsequently corrected by using a square root data transformation (Tabachnick \& Fidell, p. 84). 
CHAPTER FOUR

RESULTS AND DISCUSSION

\section{Survey Response}

The survey response rate was $40 \%$. One hundred and three providers (of a total of 257 providers) responded. of the returns, 88 (34\%) were fully completed and 15 (15\%) identified themselves as no longer in clinical practice, retired or in research exclusively. Nine of the completed surveys were omitted since they met the exclusion criteria of working less than 8 clinical hours/week. Of those fully completed, $89 \%$ were used in the final sample $(\mathrm{N}=79)$. This is a fairly good response rate, especially given the length of the survey ( 7 pages). Thirty one percent of the full sample $(N=79)$ were included in the analyses.

Caution should still be used in generalizing from the results since $40 \%$ of the providers responded and since the sample of licensed psychologists was drawn from a small portion of the united states. Since the survey was strictly anonymous and there is no additional information about the sample, there is no way in this study to compare responders with nonresponders.

The survey period was July 23, 1991 to October 2, 1991. 


\section{Descriptive statistics}

Frequencies and counts were obtained for demographic information. Means, standard deviations and intercorrelations were obtained for the three demographic variables (age, gender and children), job autonomy and the DV (burnout subscales: Emotional Exhaustion, Personal Accomplishment, Depersonalization). Relevant results are presented in Table 2. Similar information for measures that were not the main focus of this study are discussed in additional sections. 


\section{Demographic Information}

Table 2: Basic Demographic Information of Sample $(N=79)$

Count Percent

Gender

Male

Female

Age Groups

$$
\begin{aligned}
& \text { Below } 25 \\
& 26-30 \\
& 31-40 \\
& 41-50 \\
& 51-60 \\
& 60+
\end{aligned}
$$

$\begin{array}{rr}3 & 3.88 \\ 1 & 1.38 \\ 34 & 43.08 \\ 36 & 45.68 \\ 3 & 3.88 \\ 2 & 2.58\end{array}$

Marital status

Single

Married

Divorced

Separated

widowed

$\begin{array}{rr}5 & 6.3 \% \\ 66 & 83.5 \% \\ 5 & 6.3 \% \\ 1 & 1.3 \% \\ 2 & 2.5 \%\end{array}$

Children

Yes 57

72.18

No

State (Primary Practice)

Rhode Island

Massachusetts

Connecticut

Highest Degree

PhD

EdD

Misc

(one each:

MD, PSYD, MA, CAGS, MEd)

Typical clientele

Inpatient

outpatient

69

8

2

$87.3 \%$

$10.1 \%$

$2.5 \%$

70

4

5

4

62

Both inpatient \& outpt
5.18

$78.5 \%$

16.58 
Table 2 continued:

Basic Demographic Information of Sample $(N=79)$

Count Percent

\begin{tabular}{lrr}
\hline Current work setting & & \\
Managed Health orgzn & \multicolumn{1}{c}{4} & $5.1 \%$ \\
Government Facility & 7 & $8.9 \%$ \\
Private Practice & 58 & $73.4 \%$ \\
Misc-did not specify & 10 & $12.7 \%$ \\
three above (e.g., school & & \\
hospital, counseling cntr) & \\
Setting size & & \\
Solo & 35 & $44.3 \%$ \\
Partnership & 6 & $7.6 \%$ \\
Small Group (3-5) & 14 & $17.7 \%$ \\
Medium Group (6-15) & 5 & $6.3 \%$ \\
Large Group (15+) & 19 & $24.1 \%$
\end{tabular}

Additional Information

Mean

SD

Hours per week spent on clinical job.

Years of experience as a therapist.

34.6

14.4

13.6

6.8

Psychologists participating in this study were $63 \%$ male ( $37 \%$ female). The mean age of participants was 41 years old and $83 \%$ were married; $72 \%$ had children. Most had their primary clinical practice in Rhode Island (87\%) and most had outpatient clients (798). Most worked in private practice $(73 \%)$ and the most common setting size was solo practice (44\%). The modal number of hours worked per week (including part-time and full-time participants was 40 hours per week (25 participants worked more than forty hours per week). 


\section{Correlation Analyses}

Preliminary support for some hypotheses and relationships is provided by the pattern of associations in Table 3. Descriptions below refer to the correlation matrix.

Table 3

Intercorrelations of the Four Criteria and the Three Subscale Measures of Burnout ( $N=79$ )

\begin{tabular}{|c|c|c|c|c|c|c|c|}
\hline & Autonomy & Age & Gender & Children & $E E$ & PA & DP \\
\hline $\begin{array}{l}\text { Autonomy } \\
\text { Age } \\
\text { Gender } \\
\text { Children } \\
\text { EE } \\
\text { PA } \\
\text { DP } \\
\text { Satisfaction }\end{array}$ & $\begin{array}{l}-.03 \\
.11 \\
-.06 \\
-.37 \star \star \\
.13 \\
-.33 \star \star \\
.15\end{array}$ & $\begin{array}{l}-.28 \star \\
.34 \star \star \\
-.19 \\
.30 \star \star \\
-.09 \\
-.06\end{array}$ & $\begin{array}{l}-.35 \star \star \\
-.36 \star \star \\
.01 \\
-.11 \\
.24 \star\end{array}$ & $\begin{array}{l}.06 \\
.31 \star \star \\
-.04 \\
.03\end{array}$ & $\begin{array}{l}-.22 \\
.36 \star \star \\
-.29 \star \star\end{array}$ & $\begin{array}{l}-.21 \\
.33 * \star\end{array}$ & .02 \\
\hline $\begin{array}{l}\star \text { Significant } \\
\star \mathrm{r}>.2216, \mathrm{p}= \\
\text { df } \mathrm{N}-2=77 \\
\text { Note: Burnout } \\
\text { (2) PA - Perso } \\
\text { Gender - (1) } \\
\text { Children - (0) } \\
\text { Autonomy and }\end{array}$ & $\begin{array}{l}\text { at the } \\
.05 \\
\text { subscales } \\
\text { nal Accom } \\
\text { ale, ( } 2) \\
\text { no child } \\
\text { satisfac }\end{array}$ & $\begin{array}{l}.01 \text { lev } \\
\text { as are ( } \\
\text { mplishm } \\
\text { female } \\
\text { dren, ( } \\
\text { action }\end{array}$ & $\begin{array}{l}\text { el: } r> \\
\text { 1) EE - } \\
\text { ent and } \\
\text { 1) prov: } \\
\text { Scales: }\end{array}$ & $\begin{array}{l}.2885, \mathrm{p}= \\
\text { Emotional } \\
\text { (3) DP } \\
\text { ider has } \\
\text { : High sc }\end{array}$ & $\begin{array}{l}=.01 \\
l \text { Exhau } \\
\text { - Deper } \\
\text { Childre. } \\
\text { cores }\end{array}$ & $\begin{array}{l}\text { stion } \\
\text { sonaliza }\end{array}$ & $\begin{array}{l}\text { tion. } \\
\text { high }\end{array}$ \\
\hline
\end{tabular}




\section{Correlation of Job Autonomy with Burnout Subscales}

Results of the correlation analyses show some significant correlations of burnout with autonomy. A correlation of -.37 was obtained for autonomy and Emotional Exhaustion and -.33 for autonomy with Depersonalization.

\section{Correlation of Demographics with Burnout Subscales}

A significant correlation of .30 was obtained for age with Personal Accomplishment and a significant correlation of -.36 was obtained for gender with Emotional Exhaustion. Findings show a sense of personal accomplishment increases with age. Emotional Exhaustion is more prevalent among men in this sample (however, gender was unequally distributed: $63 \%$ men and $37 \%$ woman).

\section{Correlation of Job Autonomy with Setting size}

Setting size and job autonomy were negatively intercorrelated $(r=-.34, p<.01)$, meaning that less job autonomy was experienced in the larger settings.

\section{Correlations with Job Satisfaction}

Job satisfaction is negatively correlated with Emotional Exhaustion ( $r=-.29, p<.01$ ) and positively correlated with personal accomplishment $(\mathrm{r}=.33, \mathrm{p}<.01)$. In other words, high job satisfaction is associated with low emotional exhaustion and high personal accomplishment. 
Job satisfaction is negatively correlated with providers considering leaving their clinical profession ( $r=-.54, p<.01)$ and providers leaving due to increased controls and regulations $(r=-.37, p<.01)$. In a related correlation, providers wanting to leave their clinical profession correlates with Emotional Exhaustion $(x=.40$, $\mathrm{p}<.011$.

In summary, these intercorrelations lend credibility to the construct validity of burnout. It is logical that burnout would correlate negatively with Job satisfaction and positively with wanting to leave the profession. Additionally, it makes sense that high job satisfaction would correlate positively with increased personal accomplishment. Having children is associated with personal accomplishment.

\section{Insignificant correlations}

Background characteristics of marital status, household income and the number of children at home had small insignificant associations with burnout and autonomy.

Interestingly, attitudes toward controls (alpha $=.72$; nine items) did not correlate with any variables, yet these items did form an internally consistent scale. This suggests that professed attitudes on the political-economic level do not correlate with measures such as burnout, 
satisfaction, autonomy and demographic variables as assessed in this study. For example, favoring controls did not correlate with any observed reduction in burnout. Attitudes toward controls was omitted from the regression analysis due to this non-significant finding.

\section{Intercorrelations of Burnout Subscales}

Two subscales of burnout significantly intercorrelate (Emotional Exhaustion and Depersonalization; $r=.36$, $\mathrm{p}<.01$ ) 82). Multicollinearity (almost perfectly correlated variables) did not exist; the two subscales did not have similar patterns of correlations with other variables (Tabachnick and Fidell, 1983, p. 82).

\section{Importance of Autonomy}

How providers value professional autonomy was assessed by summing four items, asking how important was their ability to choose type of treatment, type of clients, length of treatment and fee. This measure was not used in any analyses. It was used as a check to validate the construct of autonomy - that professional autonomy is important to providers. Results show that all providers judged professional autonomy as important:

95\% Judged autonomy either "very important" or "generally important"*

5\% Judged autonomy as "somewhat important"

o\% judged autonomy as "not too important"

0\% judged autonomy as "not at all important" 
(* Note: 56\% judged professional autonomy as "very important")

On this scale, no respondent's summed score fell into the final two categories "not too important" and "not at all important", although a few answered in those categories to isolated items.

This information helps to validate that autonomy is important to providers. Psychologists' decreased professional autonomy would indicate a reduction or loss of this value. This logically fits the model which suggests that loss of autonomy would be reflected in a burnout measure.

Importance of autonomy in specific areas can be found in Table 4.

Table 4: Importance of Autonomy

\begin{tabular}{|c|c|c|c|}
\hline $\begin{array}{l}\text { Importance of } \\
\text { Autonomy Items }\end{array}$ & $\begin{array}{l}\text { Jery \& } \\
\text { Generally } \\
\text { Important }\end{array}$ & $\begin{array}{l}\text { Somewhat } \\
\text { Important }\end{array}$ & $\begin{array}{l}\text { Not at all } \\
\text { Important }\end{array}$ \\
\hline Choosing type of treatment & $99 \%$ & $1 \%$ & $0 \%$ \\
\hline $\begin{array}{l}\text { Choosing type of clients } \\
\text { you treat }\end{array}$ & 958 & $4 \%$ & 18 \\
\hline choosing length of treatmer & ent $86 \%$ & $13 \%$ & 18 \\
\hline Choosing own fee & $82 \%$ & 148 & 48 \\
\hline
\end{tabular}


This table clearly demonstrates that respondents value autonomy highly, although there are some differences in how highly they value aspects of their practice. Autonomy over treatment modality and choice of clients is valued somewhat higher than autonomy over length of treatment and cholce of fee; however, all four aspects are highly valued.

\section{Statistical analysis of the Hypotheses}

For the main analyses (multiple regressions), the dependent variable was the raw summed score on one of the three MBI scales (Emotional Exhaustion, Personal Accomplishment and Depersonalization). The independent variables consisted of a block entry of demographic varlables (age, gender and children) followed by entering the main IV of interest, current job autonomy. Separate analyses were done for each subscale of the MBI to determine the importance of job autonomy in predicting burnout. Following this procedure, a second series of multiple regressions was computed to determine the best combination of variables for predicting burnout and which were unimportant to the regression equation. The same four variables (age, gender, children and job autonomy) were entered together into the equation (standard multiple regression). Then a backwards regression was done to eliminate all but the variables most significant and predictive of burnout. This again was done separately for 
each of the subscales.

Some authors have suggested that burnout is a related but distinct concept from job dissatisfaction and decreased autonomy. Freudenberger (quoted in Mangano, 1982, p. 73) states that "satisfied employees are the ones who know what's expected of them....They feel significantly involved and have a reasonable amount of input in decisions that affect them..." He continues, "In a positive work atmosphere there is more autonomy and less red tape". Effects of a "negative environment" include dissatisfied employees who have "only a vague sense of their job responsibilities, lack autonomy, and do not trust or work with their colleagues. (quoted in Mangano, 1982, p. 16). Sustained job dissatisfaction and diminished autonomy are implicated in burnout.

The following a posteriori exploratory factor analyses were done to add to an understanding of the relationship between related variables of interest in this study (Tabachnick \& Fidell, 1983). First, nine hypothetically related survey variables were entered into the analysis to assess for possible factor structure. Next, a final factor analysis focused on the five measures of primary interest, job autonomy, job satisfaction and the three burnout subscales. This analysis was done to assess factor structure or relatedness among the primary variables of interest. This analysis was also used as a means of construct validation. 
Additional analyses were done to investigate exploratory questions of interest. They are discussed in chapter five.

\section{Regression Analyses}

Hypothesis 1: Autonomy and Emotional Exhaustion

A multiple regression analysis (Tabachnick \& Fidell, 1983; Norusis, 1988) was used to assess the relative importance of autonomy to burnout (Emotional Exhaustion), after using a block entry of personal characteristics into the equation (gender, age and children). A linear relationship was found, with age, sex and autonomy accounting for $33 \%$ of the observed variance in burnout (Emotional Exhaustion).

Looking at the Beta weights, the most important predictor in the equation is gender (Beta $=-.41)$. The rest of the predictors, in order of importance are job autonomy (Beta $=-.33)$ and age $($ Beta $=-.32)$. Having children is not a predictor of Emotional Exhaustion (Beta=.005).

Testing the significance of these predictors by the $F$ ratio of each Beta weight, gender, autonomy and age turn out to be significant, whereas having children is nonsignificant. See Table 5 . 
Table 5: Standardized Multiple Regression Coefficients as Predictors of Emotional Exhaustion Subscale of MBI with Standard Errors in parentheses $F$ ratios and significance of $F(N=79)$

\begin{tabular}{lll}
\hline variable & $\begin{array}{l}\text { Standardized } \\
\text { correlation coefficient } \\
\text { Standard Errors in parentheses }\end{array}$
\end{tabular}

$\begin{array}{lrrr}\text { Age } & -.32 & (.915) & 9.39 * * \\ \text { Gender } & -.41 & (1.63) & 15.65 * \star \\ \text { Children } & .00 & (.005) & .00 \\ \text { Autonomy } & -.33 & (.225) & 11.90 * *\end{array}$

$\star \star$ FCrit $(1,74)=6.99, \mathrm{p}<.01$

Gender - (1) male, (2) female.

Children - (0) no children

(1) provider has children.

Autonomy: High scores reflect high autonomy.

\begin{tabular}{ll}
\hline Summary & statistics: \\
Multiple R & .5743 \\
R Square & .3298 \\
Adj R Square $\quad .2936$ \\
\\
$F(4,74)=9.105$ \\
Significance of $F(4,74)=.0000, p<.01$
\end{tabular}

Fcrit $(4,74)=3.58, p=.01$

The $F$ ratios of gender, job autonomy and age all exceed the critical value and therefore are significantly important to the prediction of Emotional Exhaustion.

The $R$ squared, which determines how well all four predictors as a set are doing in prediction of Emotional Exhaustion, is .33. This means that $33 \%$ of the variance in Emotional Exhaustion can be accounted for by this set of predictors. This set of predictors is statistically significant $F(4,74)=9.11, p<.01$. From this overall $F$ test, children could be eliminated without losing much in 
predictability. Looking at the correlation matrix, children does intercorrelate significantly ( $p$ <.01) with both age and sex and apparently is reflecting a lot of shared variance in the Beta score.

In a follow-up backwards analysis (Norus1s, 1988), children was the only variable removed from the equation, leaving gender, age and autonomy as the best predictors of Emotional Exhaustion in this equation. All three were significant at the .01 level with the following overall statistics after removal of the variable, children.

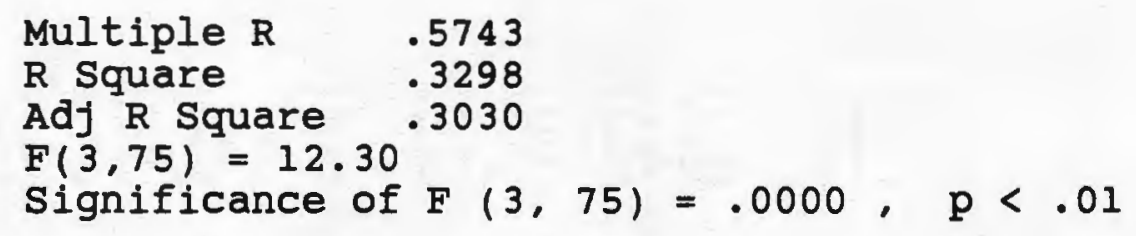

The null hypothesis of no linear relationship was rejected. In summary, being younger in age, having a male gender and lower autonomy all contributed significantly ( $p$ <.01) to Emotional Exhaustion. Caution needs to be exercised in interpreting the gender variable due to the uneven distribution of gender in the sample (63\% males, $37 \%$ females). Job autonomy was found to predict Emotional Exhaustion (burnout subscale). 
Hypothesis 2: Autonomy and Personal Accomplishment

A multiple regression analysis was used to assess the relative importance of autonomy to burnout (Personal Accomplishment), after using a block entry of personal characteristics into the equation (sex, age and children). A linear relationship was found, with age, sex, children and autonomy accounting accounting for $19 \%$ of the observed variance in burnout (Personal Accomplishment).

Looking at the Beta weights, the most important predictor in the equation is children (Beta $=.29$ ). The rest of the predictors, in order of importance are age $($ Beta $=.25)$, gender $($ Beta $=.17)$ and job autonomy (Beta $=$ .14),

Testing the significance of these predictors by the $F$ ratio of each Beta weight, none of the predictors of Personal Accomplishment are significant at the .01 level. Table 6 shows the results. 


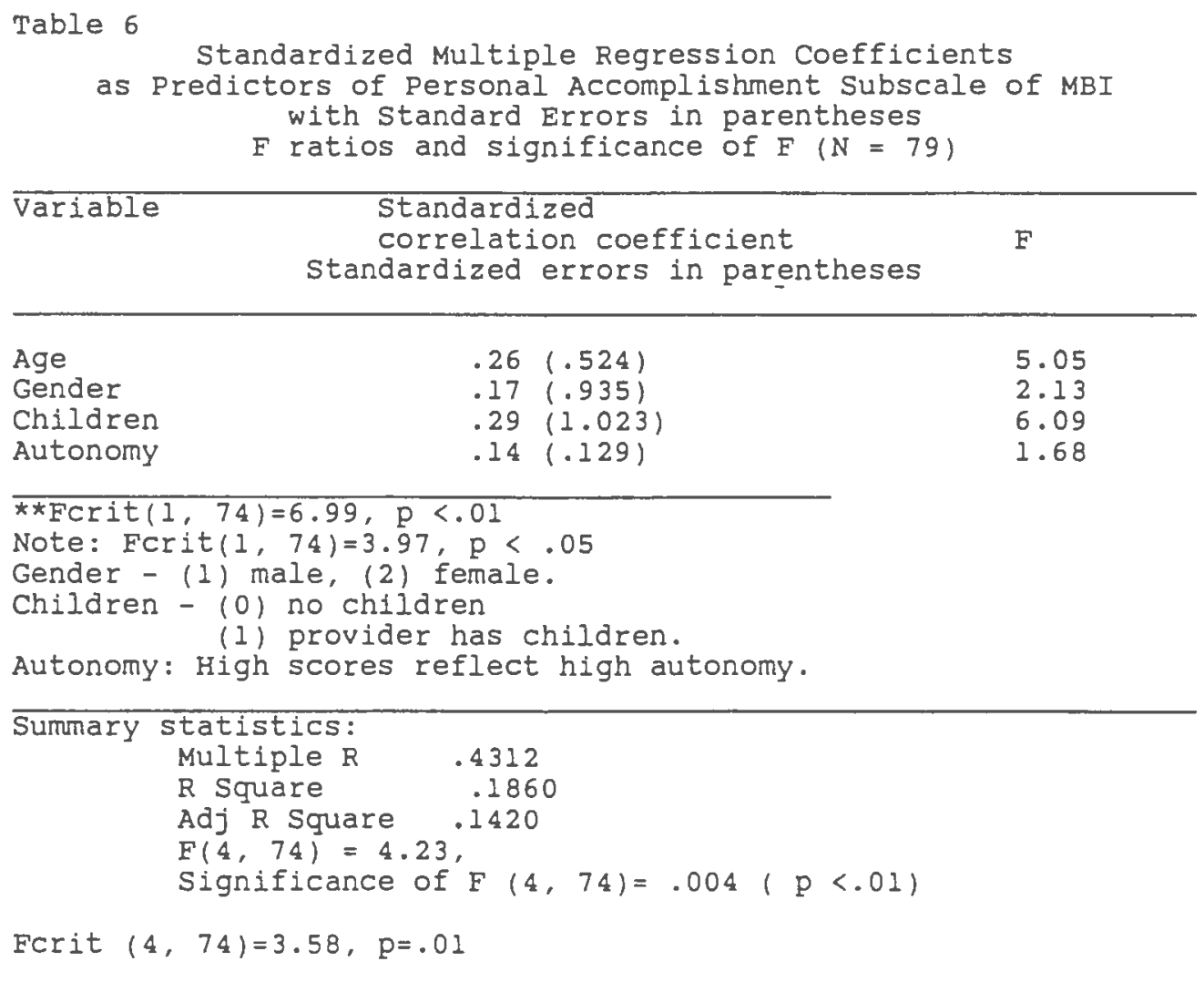

The $R$ squared, which determines how well all four predictors as a set are doing in prediction of Personal Accomplishment is .19. This means that 198 of the variance in Personal Accomplishment can be accounted for this set of predictors. This is statistically significant F(4, $74)=4.23, \mathrm{p}<.01$. 
Although age, gender, children and autonomy do not individually contribute to Personal Accomplishment, as a set of predictors, the four variables do significantly contribute $(.01$ level). This means that one's age, sex, having children and job autonomy were not individually related to burnout at the .01 level. The null hypothesis regarding individual predictors was therefore not rejected. The null hypothesis for the overall set of predictors is rejected; the set of predictors does significantly account for $19 \%$ of the variance in Personal Accomplishment. This might be better understood by noting that at the .05 significance level, both age and children significantly predict burnout. This finding is consistent with other studies suggesting that as one gets older, one generally feels more of a sense of personal accomplishment; also having children adds to ones sense of personal accomplishment (Maslach and Jackson, 1985).

In a follow-up backwards analysis, autonomy and gender were sequentially removed from the equation, leaving age $F(2,74)=3.10$, and children $F(2,74)=4.19$ as the best predictors of Personal Accomplishment. The resulting significance of individual predictors was greater than .01, although the resulting combination of these two predictors in the equation is significant $F(2,74)=6.17$, significance of $F=.003$ and accounts for 148 of the observed variance in Personal Accomplishment. In this case, age and children are not significant as individual 
predictors but are significant predictors of Personal Accomplishment in combination. Summary statistics are listed below.

$\begin{array}{lr}\text { Multiple R } & .3736 \\ \text { R Square } & .1396 \\ \text { Adj R Square } & .1170 \\ \text { F }(2,74)=6.17\end{array}$

Significance of $F(4,74)=.0033$

For the overall analyses, the null hypothesis of no linear relationship was rejected.

\section{Hypothesis 3: Autonomy and Depersonalization}

A multiple regression analysis (Tabachnick \& Fidell, 1983) was used to assess the relative importance of autonomy to burnout (Depersonalization), after using a block entry of personal characteristics into the equation (sex, age and children). The demographic block variables were not significant $[R$ square=.03, Significance of $F$ (4, $74)=.51]$. Next, Job autonomy was entered into the regression and the $R$ squared increased to .14, $[F(4,74)=2.91$, significance of $F=.027]$. No linear relationship was found between age, sex, children, autonomy and Depersonalization; the null hypothesis was therefore not rejected (non-significant at the .01 level)

Looking at the Beta weights, the most important predictor in the equation is job autonomy (Beta $=-.33$ ). The rest of the predictors, in order of importance are sex, 
age and children (Beta's less than .13)

Testing the significance of these predictors by the $F$ ratio of each Beta weight, only job autonomy is significant at the .01 level $[F(1,74)=9.03]$. Gender, autonomy and age are non-significant, falling within the range of chance. Table 7 shows the results.

Table 7

Standardized Multiple Regression Coefficients

as Predictors of Depersonalization Subscale of MBI with Standard Errors in parentheses

$F$ ratios and significance of $F(N=79)$

\begin{tabular}{lrr}
\hline Variable & $\begin{array}{c}\text { Standardized } \\
\text { correlation coefficient } \\
\text { Standard error in parentheses }\end{array}$ & \\
\hline Age & $-.11(.120)$ & .872 \\
Gender & $-.13(.214)$ & 1.203 \\
Children & $-.07(.234)$ & .314 \\
Autonomy & $-.33(.029)$ & $9.030^{*}$
\end{tabular}

ॠFCrit $(1,74)=6.99, \mathrm{p}<.01$

Gender - (1) male, (2) female.

Children - (0) no children

(1) provider has children.

Autonomy: High scores reflect high autonomy.

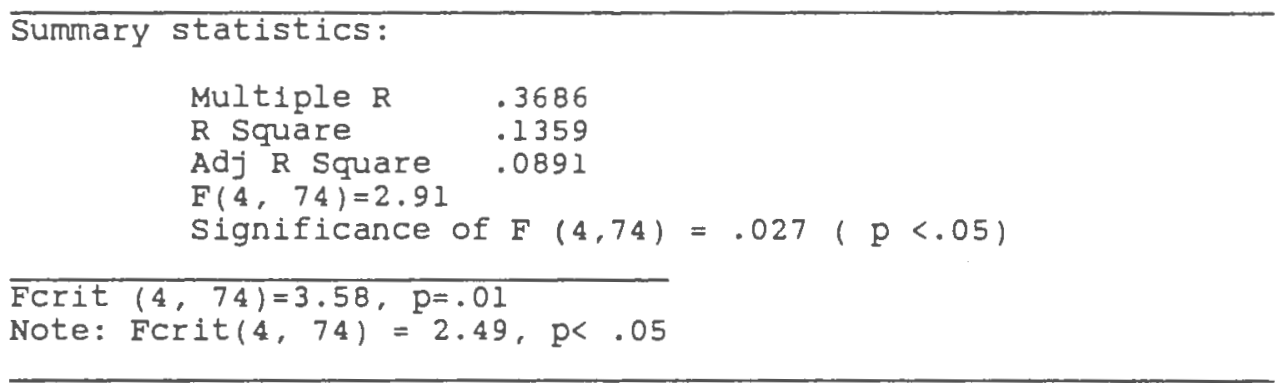


Only the $F$ of Job autonomy exceeds critical value and therefore is significantly important as a predictor of burnout.

The $R$ squared, which determines how well all four predictors as a set are doing in prediction of Depersonalization is .14. This means that $14 \%$ of the variance in Depersonalization can be accounted for by this set of predictors. This is statistically significant $[F(4,74)=2.91 \mathrm{p}<.01]$.

In a follow-up backwards analysis, children, sex and age were sequentially removed from the equation, leaving autonomy $[$ Beta $=-.33, F(1,77)=9.67, p<.01]$ as the best predictor of Depersonalization. The resultant backward multiple regression suggests that autonomy accounts for $11 \%$ of the observed variance in burnout (Depersonalization). overall results are listed below.

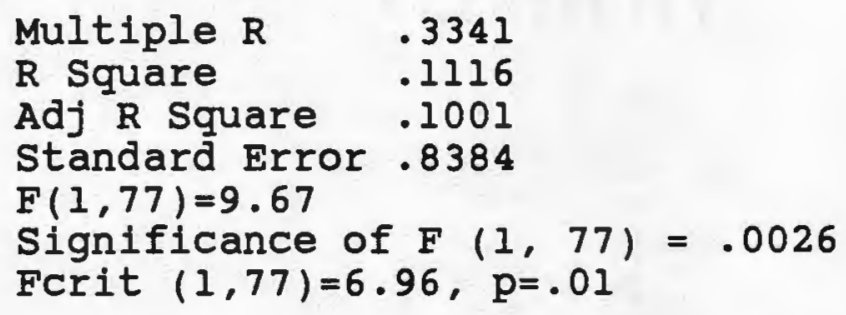

For the backward analyses, the null hypothesis of no linear relationship was rejected. Autonomy is a predictor of burnout -Depersonalization; however, age, gender and children are not significant predictors. 


\section{Factor Analyses}

Factor analyses, using varimax rotations, were used to assess possible structure and relatedness between constructs. Orthogonal rotation was chosen for the ease of description and for conceptual simplicity (easier to understand than oblique rotations). SPSSX FACTOR was used to perform the analyses.

It was suggested by Freudenberger (1975) that burnout is distinct, although related to job dissatisfaction. The relationship between these measures and similar ones were assessed by two separate factor analyses.

\section{Hypothesis 4: Central and Demographic Variables}

In the first factor analysis, eight variables were entered into the equation. They are job autonomy, Job satisfaction, attitude toward controls, the three burnout subscales (Emotional Exhaustion, Personal Accomplishment, Depersonalization and two demographic variables, age and gender. A three factor solution was obtained accounting for $59.1 \%$ of the variance. Factor 1 (Job autonomy, Emotional Exhaustion and Depersonalization) accounts for the most variance in the solution (26\% with an eigenvalue of 2.08 ).

Attitudes toward controls appears to be an outlier variable; its factor loading is .40 which is less than the .50 cutoff chosen for inclusion of a variable for interpretation of a factor. Apart from this one variable, 
all other factor loadings are in the very good to excellent range (Tabachnick and Fidell, 1983, p. 411), meaning that factor loadings account for more than $40 \%$ to $50 \%$ of the variance that each factor contributes to the observed variable. Excellent range are $>.71$ (explaining $50 \%$ of the variance); very good range is $>.63$ (explaining $40 \%$ of the variance); good range is $>.55$ (explaining $30 \%$ of the variance. No multicollinearity was found (no eigenvalues close to zero) and the factor matrix is factorable (correlations in excess of .30). Communalities range from $.55-.87$, with the exception of the control variable (.19).

Table 8

Component Measures, Rotated Factor Loadings, Communalities (h2) and Factor SSLs (sum of squared loadings for each rotated factor)

\begin{tabular}{|c|c|c|c|c|}
\hline Factors 1 to 3 & $E I$ & $\overline{\mathrm{F} 2}$ & $\overline{F 3}$ & Communality \\
\hline $\begin{array}{l}\text { Depersonalization } \\
\text { Job Autonomy } \\
\text { Emotional Exhaustion } \\
\text { Attitude twd Controls }\end{array}$ & $\begin{array}{r}.75 \\
-.72 \\
.69 \\
(.40)\end{array}$ & & & $\begin{array}{l}.63 \\
.55 \\
.61 \\
.19\end{array}$ \\
\hline $\begin{array}{l}\text { Age } \\
\text { Children } \\
\text { Personal Accomplishmen }\end{array}$ & & $\begin{array}{l}.79 \\
.74 \\
.59\end{array}$ & -.53 & $\begin{array}{l}.64 \\
.58 \\
.66\end{array}$ \\
\hline Job Satisfaction & & & -.93 & .87 \\
\hline SSL & 1.56 & 1.52 & 1.15 & \\
\hline \multicolumn{5}{|c|}{$\begin{array}{l}\text { To facilitate interpretability, variables have been ordered by } \\
\text { size of loading, and loadings less than .50 (258 variance) are } \\
\text { left blank, except for the Attitudes towards controls variable. } \\
\text { The remaining unmarked loadings range from.04-.34. } \\
\text { Note: Children- (0) no children, (1) provider has children. } \\
\text { Autonomy and Satisfaction Scales: High scores reflect high } \\
\text { autonomy and high satisfaction. }\end{array}$} \\
\hline
\end{tabular}


Factor SSLs are greater than one. This is an estimate of the reliability of the factor (each variable has a standardized eigenvalue of 1 ; factors must exceed this to be a better indicator than a variable).

Orthogonal rotation revealed three factors (see Table 8 above). Factor one is the strongest factor, indicating that Emotional Exhaustion and Depersonalization subscales of burnout are strongly negatively correlated with job autonomy. Rotation plots suggest a simple structure for this factor, with variables fairly independent of other factors

The Personal Accomplishment subscale of burnout loads on two factors (Factor 2 and 3 ) suggesting this subscale is a complex variable. Factor 2 indicates that provider's age, having offspring and feelings of personal accomplishment possibly tap into a broader latent variable having to do with accomplishment.

Caution must be exercised with Factor 3 since it is a two variable factor, making it less reliable. Checking the correlation matrix, $R$, the two variables do correlate significantly $(r=-.33)$ at the .01 level. Examining patterns of correlations among other variables, Personal Accomplishment has insignificant, low magnitude correlations with Factor 1 variables (Job Autonomy, Depersonalization, Emotional Exhaustion). Personal Accomplishment also has significant correlations with variables on Factor 2 (with age $r=.31 * \star ;$ with children 
$r=.31 * *)$. This again suggests that Personal Accomplishment is a complex variable in this factor solution.

\section{Hypothesis 5: Central variables}

In a second factor analysis, using the central hypothetically related variables, (job autonomy, job satisfaction and the three burnout subscales: Emotional Exhaustion, Personal Accomplishment and Depersonalization), similar factors obtain.

Factor analysis, with varimax rotation, was performed on the above 5 variables. A two factor solution was obtained accounting for $61.8 \%$ of the variance. Factor 1 accounted for most of the variance in the solution (39.3\%) with an eigenvalue of 1.97. There were no outliers among the variables and no multicollinearity. The correlation matrix was factorable.

Rotated factor loadings are in the very good to excellent range (Tabachnick and Fidell, 1983, p. 411) meaning that the loadings account for more than 40\%-50\% of the variance that each factor contributes to the observed variable as shown in Table 9 . 
Table 9

Component Measures, Rotated Factor Loadings; Communalities (h2) and Factor SSLs (sum of squared loadings for each rotated factor)

Factor 1 Factor 2 Communality

$\begin{array}{lll}\text { Depersonalization } & .81 & .66\end{array}$

Job Autonomy $\quad-.73 \quad .55$

Emotional Exhaustion $.66 \quad .58$

Job Satisfaction $\quad-.87 \quad .76$

Personal Accomplishment $\quad-.70 \quad .53$

$\begin{array}{lll}\text { SSL } & 1.63 & 1.25\end{array}$

To facilitate interpretability, variables have been ordered by size of loading, and loadings less than .50 (25\% varlance) are left blank, except for the attitudes towards controls variable. The remaining unmarked loadings range from .01-.38.

Note: Children- (0) no children, (1) provider has children. Autonomy and Satisfaction Scales: High scores reflect high autonomy and high satisfaction.

Rotation plots reveal a simple structure for both factors and across variables, Emotional Exhaustion being the only variable that shows slight complexity. As in the previous factor analysis, job autonomy and two subscales of burnout load on factor 1 . Likewise, job satisfaction and Personal Accomplishment load on factor 2. Tabachnick and Fidell (1983) caution that two variable factors must be interpreted with extra caution as previously mentioned. However, with additional examination, the findings of Factor 2 indicate reliability. From the $\mathbf{R}$ matrix, they are significantly intercorrelated with each other $(r=.33)$ and have low correlations $(r<.30$ ) with all other variable.

Communality values seen in Table 9 range from .53 to 
.76 suggesting that the total percent of variance in the observed variables accounted for by the two factor model items was sufficiently homogeneous to load on variables leaving no outlying variables. SSLs are >1, (1.97 for Factor 1; 1.12 for Factor 2). This is an indicator of reliability of the factors.

In summary, job satisfaction and personal Accomplishment factor together in both analyses. This finding supports the construct validity of the burnout measure of Personal Accomplishment.

Depersonalization, fob autonomy and Emotional Exhaustion factor together which adds to construct validity of the two burnout subscales. Findings suggest that Depersonalization and Emotional Exhaustion are related to each other and to job autonomy. 


\section{CHAPTER FIVE}

\section{ADDITIONAL RESULTS OF THE SURVEY}

Several interesting findings in the current survey lend depth to the understanding of the relationship between provider autonomy and burnout. A brief presentation and discussion of these findings are included in the sections below. The sections cover provider preferences toward payment method and setting type, provider attitudes toward controls, reimbursement items, personal preferences for health care, value items, satisfaction items and autonomy items.

The final section in this chapter discusses the interesting comments that providers made on their surveys in an optional section. The question they answer is "If you could influence the direction of your clinical practice in the next five years, what would you encourage, improve upon or change?". This was an opportunity to understand their experiences and what they consider important by use of qualitative data. Qualitative data is also presented regarding provider preferences and attitudes toward setting type and pay option. 


\section{Psychologists Choosing to Leave the Profession}

There are multiple causes of burnout and of providers choosing to leave the profession. Questions were included on the survey allowing providers to select the two most important causes from a variety of 12 competing options (new interests, work overload, less control over decision making in my clinical practice, third party or government intervention-regulations and controls, personal family problems, poor physical health, poor mental health, difficult clients, low peer support, lack of promotion opportunities and few opportunities to do original creative work). Results are listed in Table 10.

of the entire sample ( $N=79) \quad 37 \%$ (29) agreed with the statement "I have recently (in the past year) felt like leaving my clinical profession.". An additional $28 \%$ (22) indicated uncertainty or mild disagreement. Those firmly not considering leaving represented $35 \%$ (28) of the sample.

of those in the first two categories checking off reasons for their considering leaving the profession, 24 providers checked off "less control over decision making in my clinical practice or third party or government intervention (e.g., regulations and controls) as their main reasons for considering leaving the profession. This represents $30 \%$ of the entire sample $(\mathrm{N}=79)$ or $47 \%$ of the more limited sample of those considering leaving the profession. Nine providers (11\% of the entire 79 
participants) checked both these options (i.e.," "less control over decision making in my clinical practice" and "third party or government intervention") as their two main reasons.

With each provider circling the two most important reasons for wanting to leave the profession, the category mentioned most frequently was "Third party or government intervention (e.g., regulation \& controls) with a total of 21 responses. Second most frequent response was "New interests" receiving 15 responses. Third most frequent response was "Less control over decision making in my clinical practice" (12 responses).

Remaining categories in order of response frequency are included in the Table 10.

Table 10

Reasons for considering leaving the profession \# responses

Third party or government intervention 21

New interests 15

Less control over decision making in my clinical practice

work overload

Few opportunities to do original creative work

Lack of promotion opportunities

Low peer support

Miscellaneous

Poor physical health:

Poor mental health

other (open-ended option)

Financial stress/low caseload 2

Prefer being with family

Too much paperwork 1

Competition from less credentialled providers 1

Lack of work

Ant of paperwork increase by Blue cross \&

total frustration trying to get reimbursement

in contract 
Two categories received no responses. These categories were "Poor physical health" and "Poor mental health".

Given the selection of response categories (12 possibilities with an open ended "other" option) providers chose the top three reasons for considering leaving the profession:

1) Third party or government intervention (e.g, regulations and controls),

2) New interests

3) Less control over decision making in my clinical practice.

The first and third responses reflect decreased autonomy- relating to outside interferences (third party and government) and to the decision making control over their practice. This finding lends support to the hypothesis regarding the importance of autonomy to staying in the profession.

Having "new interests" as the second most frequent response might reflect an average rate of career change or perhaps providers concomitantly develop alternative interests as they start to consider leaving the profession. 


\section{Provider Preferences and Attitudes}

Table 11 below summarizes the findings regarding provider preferences regarding setting type and payment method.

Table 11

Provider Preferences Regarding Setting Type and Payment $(\mathrm{N}=79)$

Setting Type Most Preferred

Private practice

(includes: solo partnership.

small or large groups)

Managed Health Care Organization

Government run facility

Miscellaneous Categories

Hospital

School

College Counseling Center

Psychiatric Hospital

Pay Options Most Preferred

Own customary fee for each service

Annual salary

Fixed fee for each service

Fixed annual amount for each patient

Capitation

Other (combo)
Count Percent

$63 \quad 80 \%$

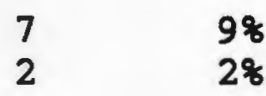

$\begin{array}{ll}4 & 58 \\ 1 & 18 \\ 1 & 18 \\ 1 & 18\end{array}$

Count Percent $40 \quad 51 \%$

$18 \quad 23 \%$

$17 \quad 21 \%$

$2 \quad 2 \%$

$1 \quad 1 \%$

$1 \quad 18$

Most psychologists preferred private practice setting (80\%) regardless of size of organization. Nine percent preferred a managed health care organization and two percent preferred a government run organization. Most preferred "own customary fee for each service" (518). Annual salary was preferred by $23 \%$ and fixed fee for each service was preferred by $21 \%$. 


\section{Attitudes towards controls}

Tables 12 and 13 report survey findings of items relating to controls.

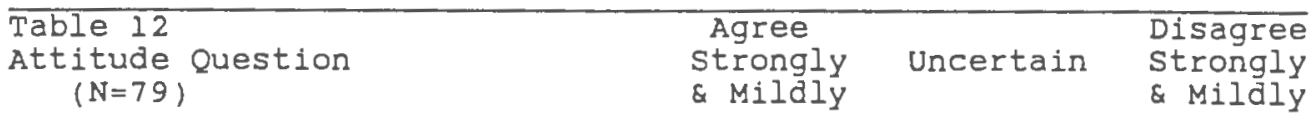

The federal government should determine how I deliver clinical mental health services (types of clients, types of treatment, fees and length of treatment).

Table 13 Percent of Psychologists Finding Controls Acceptable

\begin{tabular}{|c|c|c|c|}
\hline Control Items & $\begin{array}{c}\text { Not } \\
\text { ceptable }\end{array}$ & Uncertain & Acceptable \\
\hline $\begin{array}{l}\text { 1. Establish gov't price } \\
\text { controls for clinical } \\
\text { psychologists. }\end{array}$ & $66 \%$ & 148 & 208 \\
\hline $\begin{array}{l}\text { 2. Return to a fee for service, } \\
\text { private practice model. }\end{array}$ & 108 & 228 & 688 \\
\hline $\begin{array}{l}\text { 3. Mandate specific treatments } \\
\text { for any given disorder. }\end{array}$ & $84 \%$ & 98 & $8 \%$ \\
\hline $\begin{array}{l}\text { 4. Encourage gov't to monitor } \\
\text { clinical psychologists practices } \\
\text { levying penalties for less } \\
\text { efficient practice habits. }\end{array}$ & $e^{878}$ & $8 \%$ & $5 \%$ \\
\hline $\begin{array}{l}\text { 5. Enact legislation requiring } \\
\text { clinical psychologists acceptance } \\
\text { of medicare assignment, not } \\
\text { permitting them to charge in } \\
\text { excess of the allowable fee. }\end{array}$ & 578 & 138 & 308 \\
\hline $\begin{array}{l}\text { 6. Limit use of expensive } \\
\text { technology, such as biofeedback } \\
\text { equipment, by using a } \\
\text { "severity of need" system. }\end{array}$ & 478 & 268 & 278 \\
\hline $\begin{array}{l}\text { 7. Nationalize mental health } \\
\text { care services. }\end{array}$ & 258 & 328 & 438 \\
\hline $\begin{array}{l}\text { 8. Ration mental health care } \\
\text { services. }\end{array}$ & $87 \%$ & 98 & 48 \\
\hline
\end{tabular}


Table 13 continued:

Percent of Psychologists Finding Controls Acceptable

\begin{tabular}{|c|c|c|c|}
\hline Control Items & $\begin{array}{l}\text { Not } \\
\text { eptable }\end{array}$ & Uncertain & Acceptable \\
\hline $\begin{array}{l}\text { 9. Force providers to move to } \\
\text { underserved areas by restricting } \\
\text { the number of providers who can } \\
\text { legally bill the government in any } \\
\text { given area (use limited billing } \\
\text { numbers for each area). }\end{array}$ & $81 \%$ & 118 & $8 \%$ \\
\hline $\begin{array}{l}\text { 10. Tie licensure to willingness } \\
\text { to accept Medicare patients and } \\
\text { terms set by government. }\end{array}$ & $84 \%$ & $6 \%$ & $10 \%$ \\
\hline $\begin{array}{l}\text { 11. Encourage private certification } \\
\text { by professional organizations } \\
\text { instead of government licensure. }\end{array}$ & 408 & $28 \%$ & $33 \%$ \\
\hline
\end{tabular}

Most psychologists found government controls unacceptable. The vast majority (94\%) did not think the federal government should determine how the provider delivers mental health services (e.g., type of client, type of treatment, fees, length of treatment). Most do not want government price controls, government monitors or interference with treatment modalities. Most oppose government redistribution of providers and tying licensure to government involvement in their practice (e.g., Medicare). Most oppose placing limits on technology and 
rationing. The majority also preferred private professional certification over government licensure (although a number disagreed with this and many were uncertain).

Despite this strong vote against government interference in their profession, providers gave mixed responses when asked about nationalizing mental health services. Forty three percent found this acceptable while $32 \%$ said they were uncertain about this proposal and $25 \%$ found it unacceptable. Also, $68 \%$ of psychologists preferred a return to the private practice fee for service model with $22 \%$ uncertain and only $10 \%$ finding this unacceptable. 


\section{$\underline{\text { Reimbursement Items }}$}

Table 14 shows the findings of items pertaining to current government and 3 rd party involvement.

\begin{tabular}{|c|c|c|c|}
\hline $\begin{array}{l}\text { Table } 14 \\
\text { Reimbursement Questions }\end{array}$ & $N$ & Mean & SD \\
\hline $\begin{array}{l}\text { Average lag time between } \\
\text { services offered and gov't } \\
\text { related reimbursement }\end{array}$ & 51 & $\begin{array}{l}10.6 \\
\text { weeks }\end{array}$ & $\begin{array}{l}8 \\
\text { weeks }\end{array}$ \\
\hline $\begin{array}{l}\text { Average number of hours/month } \\
\text { of gov't-related paperwork } \\
\text { required for payment. }\end{array}$ & 63 & $\begin{array}{l}5.5 \\
\mathrm{hrs} / \mathrm{mo}\end{array}$ & $\begin{array}{l}7.7 \\
\text { hrs /mo }\end{array}$ \\
\hline $\begin{array}{l}\text { Reimbursed for time spent } \\
\text { responding to reviews (from } \\
\text { third party payers or gov't)? }\end{array}$ & 69 & $\begin{array}{l}\text { Yes: } \\
\text { No: } \\
\text { Sometir }\end{array}$ & $\begin{array}{r}3 \% \\
91 \% \\
6 \%\end{array}$ \\
\hline
\end{tabular}

This was the only section with increased missing data; results are reported with this caution. Providers spend approximately $51 / 2$ hours per month on government related paperwork required for reimbursement and they wait close to $21 / 2$ months to get reimbursement from the government. Most (91\%) are not reimbursed for time spent responding to reviews from third party payers or government. 


\section{Personal Preference}

Personal preference items are presented in Table 15.

\begin{tabular}{|c|c|c|c|}
\hline $\begin{array}{l}\text { Table } 15 \\
\text { Preference and Attitude } \\
\text { Questions }(N=79)\end{array}$ & $\begin{array}{l}\text { Agree } \\
\text { Strongly } \\
\& \text { Mildly }\end{array}$ & Uncertain & $\begin{array}{l}\text { Disagree } \\
\text { Strongly } \\
\& \text { Mildly }\end{array}$ \\
\hline $\begin{array}{l}\text { 1. If my child, spouse or parents } \\
\text { needed medical attention, I would } \\
\text { preferably want them to go to a } \\
\text { government run facility. }\end{array}$ & 08 & 138 & $87 \%$ \\
\hline $\begin{array}{l}\text { 2. If my child, spouse or parents } \\
\text { needed medical attention, I would } \\
\text { preferably want them to go to a } \\
\text { privately run facility. }\end{array}$ & 928 & $8 \%$ & $0 \%$ \\
\hline $\begin{array}{l}\text { 3. I would recommend that my } \\
\text { children or my friend's children } \\
\text { enter my profession (as a mental } \\
\text { health care practitioner). }\end{array}$ & 618 & 218 & $18 \%$ \\
\hline
\end{tabular}

Clearly, in their own personal lives, providers evaluate government medical care as inferior to private care. Not one of the 79 providers (0\%) preferred a government run facility for care of their own family. Confirming this judgment, the vast majority (92\%) preferred a privately run facility for care of their own family with none (0\%) objecting to private care. 
Most providers (61\%) would recommend their profession to their children or friend's children, although $18 \%$ would not recommend their profession and $21 \%$ were uncertain about such a recommendation.

\section{Value Items}

Table 16 presents findings of value items.

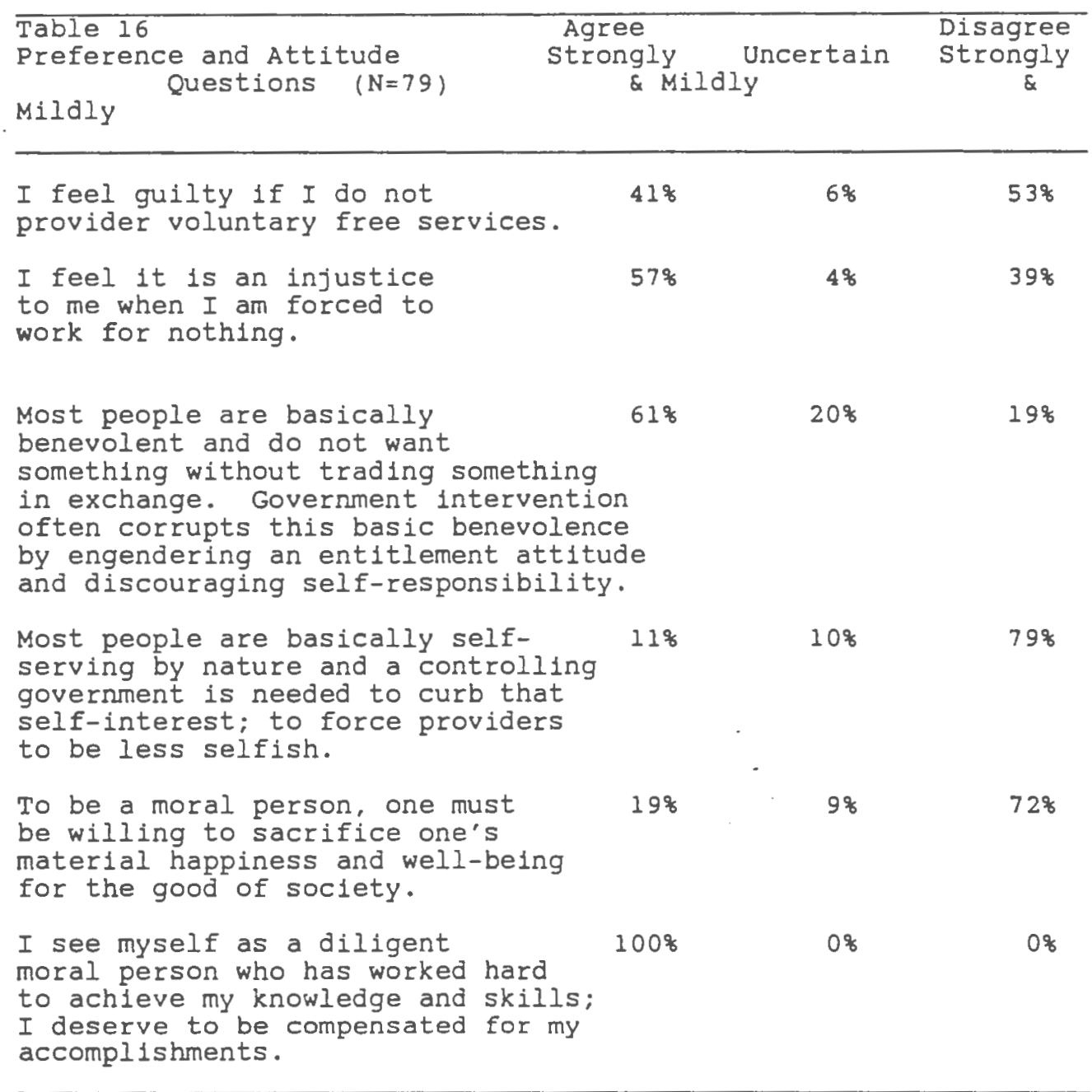


These questions are value oriented items. Although most providers felt it was injustice to be forced to work for no compensation and most did not feel guilty if not providing services without compensation, a sizable minority answered that they do feel that it is not an injustice to be forced to work for nothing and do feel guilty if not providing services for which they are not compensated.

In related value items, 728 disagreed that morality depends on self-sacrifice (sacrificing one's happiness and well being to society), $19 \%$ agreed that self-sacrifice was necessary for morality. Despite this spread of basic values (self-sacrifice vs, non self-sacrifice), all respondents (100\%) judged themselves as diligent, hard working and deserving of compensation.

of their general view of people and the role of government, approximately $80 \%$ felt that providers were not self-serving at the clients expense, requiring government force to intervene. Sixty one percent felt that people are basically benevolent, not wanting something without trading something in exchange and felt that government often corrupts this basic benevolence by engendering an entitlement attitude and discouraging self-responsibility (20\% were uncertain and 198 disagreed). A suggestion for future value questions is to separate out unique aspects of compound questions to obtain finer distinctions of provider values. This is one limitation of the current study.

Overall, with the above caution, findings show a 
spread of value orientations among providers, with the majority of respondents viewing people as benevolent and providers as ethical and many skeptical that government intervention often corrupts the relationship between providers and clients by encouraging entitlement and discouraging self-responsibility.

\section{Qualitative Data}

Providers offered many suggestions when given the opportunity to express their views. Seventy percent of the survey sample (55 providers) offered written comments in this final section of the survey.

Their answers to the following question is summarized below. They answered the question: "If you could influence the direction of your clinical practice in the next five years, what would you encourage, improve upon or change?"

Two additional optional qualitative questions were asked in the survey. They are the following:

After being asked "In which type of setting would you most prefer to work" with response categories managed health care organizations, government run facility, private practice, other, providers were asked "What are the main reasons for your preference?" A summary and list of their responses is included below. 
Providers were also asked this identical question following the item "Which pay options would you most prefer?". A summary and list of their responses in included below.

\section{Qualitative Item 1: Influence on Direction of Practice}

\section{"If you could influence the direction of your clinical practice in the next five years, what would you encourage, improve upon or change?"}

Results: The comments were replete with concerns. Many disliked gatekeepers of their profession - third party insurers, managed health care organizations and government. Specifically, many complain of the increased paperwork being ineffective, costly and a waste of time. Peer review and utilization reviews were criticized as a wasteful expenditure of funds and not effective. Control over setting of fees and clinical decision making was a major concern. Concerns about government regulations and competition from related professions were expressed. Fears of opening up or continuing private practice were noted with emphasis on difficulty getting reimbursed for one's efforts and the inability to afford possible government or third party requirements (e.g., having an MD available for approval of services).

Reliance on DSM3-R or diagnostic numbers was 
criticized since it requires giving a diagnosis to clients such as divorcing couples or remarrying couples who are otherwise healthy. Also, lack of diagnostic categories for families and inability to get reimbursed for lengthier sessions with families was a stated concern.

CEUs were criticized. Providers suggested that these mandated courses require too much time and money and need improvement.

Approximately ten percent suggested National Health Insurance or socialized medicine to help resolve many of these concerns. Their focus was on helping psychologists gain parity with the medical profession, to restrict less qualified professions from the field (e.g., social workers). This solution was also suggested as a means to take control away from insurance companies or to make sure that government mandates mental health coverage from insurance companies. Two providers mentioned increased access to mental health care. One provider suggested national licensing for psychologists while another provider suggested professional responsibility for evaluating and maintaining quality of service.

Some providers' responses focused on less heated issues (e.g., encouraging preventative behaviors) or personal goals (e.g., learn neuropsychology or work with a different population). Two respondents liked the system the way it currently is. One respondent globally commented "discourage guilt". 


\section{Qualitative item 2: Setting Preference}

In which type of setting would you most prefer to work? (circle one)

1. Managed Health Care Organization

2. Government run facility

3. Private practice (includes: solo, partnership, small or large groups)

4. Other

\section{What are the main reasons for your preference? (optional)}

The qualitative responses to the question in bold are discussed below. Thirty-four respondents chose to answer this optional question (this represents $43 \%$ of the entire sample, $N=79$ ). Only two providers ( $6 \%$ of 34 ) commented on their preference for managed health care organizations. Five mentioned preference for "other" facilities: school, psychiatric hospital, college counseling and non-profit hospital, the later liking the team approach and variety in the hospital and preferring characteristic populations found in non-profit hospitals. None (0\%) commented on a preference for government run facility. The majority, twenty seven respondents (approximately $80 \%$ of the 34 ). commented on their preference for private practice.

Summary of the results:

The results suggest that providers who responded to this qualitative item are in favor of professional autonomy. These providers prefer any size private practice over Managed Health Care Organizations or government run 
facility for reasons suggesting that autonomy is of primary importance.

A sampling of their responses indicates their preference for control of their own time, type of clients, cholce of treatment modality, control of financial compensation, expected Improved quality of care and more personal fulfillment.

Freedom from politics, bureaucracy, administrative hassles and independence from types of regulation that do not enhance treatment was a related aspect of their choice of private practice.

The concepts "autonomy" "choice" "more control" "Independence" "Increased freedom" "flexibility" which providers choose to express their preference underscore the high value that these professionals place on their independent decision-making ability and their ability to act on their conclusions without bureaucratic controls, i.e., their autonomy. Some caution is required since this optional section represents $40 \%$ of the sample; however, the consistency of reasons given for favoring private practice and the complete lack of any accolades for government-run facilities merit serious consideration and raises concern about current systemic changes. Licthenstein's finding in his review of the field (1984) that autonomy is the hallmark of professionalism, is reverberated in providers' comments. Table 17 is a complete list of their responses. 
Table 17

Responses to Qualitative Item 2: setting Preference

1. MANAGED HEALTH CARE ORGANIZATION

- Availability of other professionals for training/ consultation; less time spent on billing.

- Collegiality \& support; responsible allocation of resources.

2. GOVERNMENT RUN FACILITY: no qualitative data

3. PRIVATE PRACTICE (Solo, partnership, small or lg groups)

- Control my own time and type of client.

- Self-control

- Choice of colleagues to spend professional life with.

- Control

- Ability to set own hours, caseload size and type and freedom from bureaucracy.

- Freedom to choose type of patient, treatment and quality of care.

- Better control of quality of service

- More autonomy and personal fulfillment

- Freedom

- Independence; increased freedom

- CHOICE [provider's emphasis]

- Greatest degree of self-determination

- More control, more \$, less hassle

- Most flexibility of hours and preference for work.

- Independence from types of regulation that do not enhance tx - Greater autonomy.

- Autonomy - I really dislike being told what to do.

- Because private practice is a very minor part of my professional life.

- Autonomy, opportunity for growth, challenge of clinical work.

- Flexibility in balancing work, interests, family.

- Freedom from administrative hassles.

- Autonomy

- Avoidance of politics.

- Independence, control, flexibility.

- Freedom and flexibility of treatment modalities and types of patients.

- Flexibility in several ways.

- I am a short term therapist - very goal oriented and anti-administration.

4. Other

- Psychiatric hospital: academic affiliation w/ med school (teaching, research options, multimodal treatment options)

- Non-profit hospital: ability to work with underserved population, variety, team approach.

- Hospital -School

- College counseling center: interest, work setting, pace structured 


\section{Qualitative item 3: Payment Preference}

Which pay options would you most prefer? (circle one)

1. annual salary

2. fixed annual amount for each patient

3. fixed fee for each service

4. own customary fee for each service

5. capitation (set amount of money based on membership)

6. other

What are the main reasons for your preference? (optional)

The qualitative responses to the question in bold are discussed below. Twenty respondents chose to answer this optional question (this represents $25 \%$ of the entire sample, $N=79$ ). The majority (60\% of the 20 respondents) preferred "own customary fee for each service". Their reasons include preference of the free market, market realities, competition, preference of control (e.g., over patient care, fees, ability to set own reduced fees for poorer clients), professionalism and autonomy.

Salary was commented on by six respondents (30\% of the 20 respondents). Reasons for preferring salary included security, stability, reliability of income, being part of a larger group and freedom from having to find business, focus of attention on patient problems and removal of incentives to under or over treat.

Only one provider commented on preference for a fixed annual amount for each patient (less than 1\%) and chose this option because of increased financial incentives, 
simplicity of paperwork and flexibility with individual clients.

No one (0\%) commented on preference for capitation. One provider (less than 1\%) preferred a combination of salary and fixed annual amount for each patient with rationale that this would increase patient volume and program development.

Findings on this optional question suggest that most of those responding prefer the FFS option above all others. Mention is made of a preference for the free market, professionalism, control over patient care and setting of fees, including reduced fees and sliding scales and autonomy.

Salary was preferred by a sizable minority who chose this option for stability, freedom from finding one's own business, security, focus of attention on patients problems and protection from incentives to under or over treat.

Responses to fixed annual amount for each patient was negligible (less than 1\%) and no one responded to preference to capitation mode of payment. 
Table 18: L1st of Responses to Qualitative Item 3

1. ANNUAL SALARY

- Reliability of income

- I prefer to focus on my clinical work, not hustling for business marketing, etc and I like being part of larger group.

- Security

- stability

- Removes insidious incentives to over or under treat.

- This allows focusing of attention according to patient problem.

2. FIXED ANNUAL AMOUNT FOR EACH PATIENT

- Therapists would establish the most cost effective tx plan.

3. FIXED FEE FOR EACH SERVICE

- Increased financial incentives.

- Straight foward - easy to do paperwork - can adjust on one to one basis with client.

4. OWN CUSTOMARY FEE FOR EACH SERVICE

- Because I'm solo and part time.

- I believe in choice and a free market, etc.

- Better control of patient care.

- Professionalism; marketplace realities; competition.

- I want control over what I am paid.

- \$ incentive.

- Flexibility in adjusting fees.

- I'd like to have standard fee with option of accepting less \$ for students, those with no insurance.

- I'd like to use sliding scale and make service affordable for poorer clients, but I dislike fees set by insurance cos. like BC so I can't collect more from those who can well afford full fees.

- Greater earning potential

- Flexibility in my practice.

- Autonomy (occasional reduced fee under certain circumstances).

5. CAPITATION (set amount of money based on membership)

6. OTHER

- $1 \&$ 3: incentives to increase pt volume and program development. 


\section{CHAPTER SIX}

\section{IMPLICATIONS}

The current study takes a sympathetic look at licensed psychologists. The goal is not to learn how to better control or manage these providers, but to assess their well-being in the face of system-wide changes. Specifically, this study sought to assess the relationship between job autonomy and burnout. Psychologists' attitudes towards recent or proposed system-wide political or organizational changes are also assessed along with their preferences regarding certain practice dimensions (e.g., setting preference, pay options).

\section{Findings relating to the main hypotheses}

The principal findings of this study suggest that the level of autonomy that psychologists in this survey have over their practice is predictive of two subscales on the Maslach Burnout Inventory (Depersonalization and Emotional Exhaustion). Using regression analyses, autonomy was found to be the most important individual predictor of the Burnout subscale of Depersonalization (Beta $=-.33, p<$ .01 ). Demographic variables (gender, age and having children) were not significant. Autonomy accounted for 118 of the observed variance in Depersonalization.

The combination of variables, being younger, male, and having less autonomy, accounted for $33 \%(p<.01)$ of the 
observed variance in the Burnout subscale of Emotional Exhaustion. As individual predictors, all were significant at the .01 level (Beta for autonomy was -.33) . Having children was found to be insignificant as a predictor of this subscale.

Autonomy was not individually predictive of the Burnout subscale of Personal Accomplishment. The control variables of age and having children were found to be the strongest predictors, yet they were not individually significant. The control variables in combination with the autonomy variable did significantly contribute to the Personal Accomplishment subscale accounting for $14 \%$ of the observed variance in Personal Accomplishment.

In summary, job autonomy was predictive of Emotional Exhaustion and Depersonalization subscales on the Maslach Burnout Inventory. Autonomy was essentially not predictive of the Personal Accomplishment subscale of burnout.

These findings lend support to studies previously discussed which emphasized the value of autonomy to professionals. Previous literature highlighted autonomy as a significant factor in burnout among health care professionals (Mangano, 1982; Cherniss, 1980; Maslach, 1982) while other studies focused on the role of autonomy in Job satisfaction (Locke, 1976; Licthenstein, 1982).

Additional findings in this survey tend to strengthen the association between autonomy and burnout. When directly asked about the importance of autonomy over job 
dimensions (choice of clients in their caseload, choice of treatment, cholce of fee and cholce of length of treatment), $95 \%$ of the psychologists indicated that autonomy was either very important or generally important. Five percent judged autonomy as somewhat important and none judged autonomy as not too important or not at all important.

In another item, psychologists indicated their preference for private practice (80\%) over either managed health care organizations (9\%) or government health care facilities (2\%). Offering written reasons for their choices, psychologists mentioned their preference for control of their own time, type of clients, choice of treatment modality, control of financial compensation, expected improved quality of care and more personal fulfillment. Also mentioned was freedom from politics, bureaucracy and administrative hassles and independence from types of regulation that do not enhance treatment. They used terms including "autonomy", "choice", "more control", "Independence", "Increased freedom" and "flexibility" to express their preference for private practice. These responses are reflective of the high value providers place on self-governing, 1.e., autonomy.

In a related 1tem, $51 \%$ preferred one's own customary fee for each service over other payment options. Reasons given for this preference included a preference for the free market, professionalism, control over patient care and 
setting of fees, including reduced fees and sliding scales. Those preferring an annual salary (23\%) mentioned stability, security and freedom from market forces to focus on patient problems.

When asked whether they had considered leaving their clinical profession in the past year, $37 \%$ of the entire sample $(N=79)$ indicated they had thought of leaving; an additional $28 \%$ said they were uncertain or mildly disagreed; $35 \%$ had not considered leaving their profession. Indicating reasons for their choice, most frequently noted was "third party or government intervention le.g., regulations \& controls"; second most frequent response was "new interests" and third most frequent response was "less control over decision making in my clinical practice". The first and third categories lend support to the hypothesis regarding the importance of autonomy to staying in the profession. In the literature, studies relating to retention of physicians also found that loss of autonomy was a stated cause for leaving the profession. Prybil (cited in Licthenstein, 1984, p. 170) found that loss of autonomy ("autonomy matters: too much supervision and control") was an important reason why physicians wanted to leave a large organization. Ross (cited in Licthenstein, 1984 ) also found that turnover rates of physicians in group practices increased as centralization of management increased. There is some anecdotal evidence suggesting the importance of autonomy to staying in the profession: a 
special segment on CBS This Morning (1990) mentioned a new trend of providers leaving the profession, in part due to third party insurers and government interference. Iiterature on burnout indicates that costs of burnout include absenteeism and higher turnover rates.

Psychologists in the current study offered interesting comments in an optional section asking "If you could influence the direction of your clinical practice in the next five years, what would you encourage, improve upon or change?" Their responses expressed dissatisfaction with "gatekeepers" of their practice, dissatisfaction with increasing paperwork, peer review and utilization review. They wanted control over clinical decision making in their practice, including setting of fees and had concerns about government regulations and competition from related professions. Some psychologists suggested National Health Insurance as their suggested solution to help resolve several of these concerns. Autonomy is a theme that is reflected in many of their answers.

The literature on physician attitudes toward political and health care issues is somewhat mixed. $\mathrm{Ku}$ and Fisher (1990) found that physicians generally dislike policies that decrease their autonomy in their practice. Colombotos and Kirchner (1986) found more variation among physician views, many favoring government involvement in health care despite the fact that they were more "conservative politically than the general population" (p. 182). In the 
current study, providers' responses were somewhat varied depending on the specificity of the question asked. The vast majority (94\%) did not think the federal government should determine how they deliver mental health services (e.g., type of client, type of treatment, fees, length of treatment). Most do not want price controls or interference with treatment modalities. Most oppose redistribution of providers to underserved areas by use of limited billing numbers and most oppose tying licensure to government involvement in their practice (e.g., mandate acceptance of Medicare patients). Most oppose limits on technology and rationing of mental health care.

Despite this strong vote against government intervention in their practice, providers gave mixed responses when asked about nationalizing mental health care services. Forty-three percent find National Health Insurance acceptable; $32 \%$ are uncertain and $25 \%$ find it unacceptable. This might be reflective of current political influences. Colombotos and Kirchner (1990) convincingly argue that the political climate does affect provider attitudes. The authors comment, "The sharp change in the attitudes of physicians towards Medicare following its passage and even before physicians had any experience with the program, is testimony to the legitimizing and fait accompli effects of legislation (pp. 154-155). Licthenstein (1984) brought up the discussion of providers' adopting a defensive perspective when faced with systemic 
changes that interfere with their profession. Providers are thought to accept the "necessary evils" and accommodate to previous disliked changes by restricting their attention to possible virtues.

When the questions are more reflective of a free market viewpoint, providers tend to respond in a manner that reflects their value of autonomy. For example, most providers preferred a return to a fee for service, private practice model when the question directly asked about this.

Even more striking, when the questions reflect personal cholces, government health care does not fare well. Not even one of the 79 providers in the survey preferred a government run facility for care of their own family. A parallel item confirmed this judgment: the vast majority (92\%) preferred a privately run facility for care of their own family with none objecting to private care. It would be interesting to identify in future studies what specific aspects of public vs. private care led psychologists in this study to make these judgments.

It appears that the level at which questions are addressed affects providers' responses. This might help explain why providers can simultaneously indicate that they want government influences out of their practice (either direct government involvement or government involvement interfering with the free market, 1.e., legislation encouraging HMOs and review processes), that they have considered leaving the profession due to external controls 
and regulations, that they do not want the federal government involved in decisions regarding mental health care and that they prefer private medical care for their family over government health care - while also answering that many of them (although less than half) want some form of national health insurance, a much more politically loaded question. One possibility is that some providers might not be fully aware of the level of government involvement under a National Health Insurance or similar socialized program. Taylor (1990) provides an 1lluminating detailed account about the progressively widening government involvement under the Canadian National Health Insurance plan. The government eventually curtailed providers rights to determine their own reimbursement and even started limiting where providers could practice.

Another interesting finding related to attitudes toward controls, was that although nine items in the survey formed an internally consistent scale (Cronbach's alpha = .72) assessing attitudes toward control policies, this scale did not correlate with any survey variables, including job autonomy, the burnout subscales, job satisfaction and demographics. For example, whether one found controls acceptable or not was unrelated to one's current job autonomy and one's degree of burnout. These questions focused on "cost containment" policies and were political in nature. Politicized questions tend to be answered differently from personal or autonomy related 
questions and in this study were uncorrelated with experiences of autonomy on the job or the psychological experience of burnout.

Perhaps addressing more fundamental value questions will help to explain the somewhat conflicting responses above. An exploratory attempt was made in this paper to tap more central values but caution should be used in interpreting the results since this was not a central focus of the study and since several of these questions have a compound nature. With this caveat, the findings suggest that although most providers felt it was an injustice to be forced to work for no compensation and most did not feel guilty if not providing services without compensation, a sizable minority answered that they do feel that it is not an injustice to be forced to work for nothing and do feel guilty if not providing services for which they are not compensated. In related value items, $72 \%$ disagreed that morality depends on self-sacrifice (sacrificing one's happiness and well being to society); 198 agreed that self-sacrifice was necessary for morality. Despite this spread of basic values (self-sacrifice vs. non self-sacrifice), all respondents (100\%) judged themselves as diligent, hard working and deserving of compensation.

of their general view of people and the role of government, approximately $80 \%$ felt that providers were not self-serving at the client's expense, requiring government force to intervene. Sixty one percent felt that people are 
basically benevolent, not wanting something without trading something in exchange and felt that government often corrupts this basic benevolence by engendering an entitlement attitude and discouraging self-responsibility (20\% were uncertain and $19 \%$ disagreed). These questions were an attempt to assess more basic ideas and to understand views discussed in the literature suggesting that government or political involvement in health care can encourage "dehumanization and overutilization" (Ben-Sira, $1988)$.

Theorists suggest that the degree of control one has over one's livelihood such as with goal setting (Locke's Goal setting Theory), with relmbursement (Adam's Equity Theory and Reinforcement Theory) and with intrinsic and extrinsic rewards (Porter's and Lawler's Expectancy Theory) are all involved in work satisfaction and work motivation. Findings of the current study support the importance of autonomy to psychologists.

\section{Comments on Construct validity}

Significant intercorrelations of two subscales of burnout were noted. The Emotional Exhaustion subscale correlated with the Depersonalization subscale $(r=.36, p<$ $.01)$. This correlation suggests that these scales tap related but separate constructs.

In two factor analyses, these same two subscales significantly factored with autonomy. The third subscale, 
Personal Accomplishment, factored with job satisfaction and in one factor analyses showed a complex structure factoring with age and having offspring on one factor and with job satisfaction on the other.

\section{Iimitations of the current study}

Caution must always be used with correlational studies since they do not imply causation. The findings in this study will require additional support from subsequent studies (for reliabllity and validity purposes) with psychologists and allied professionals to increase confidence in the findings. Efforts were made to test for internal consistency of variables. The standardized Cronbach's alpha for Depersonalization is .69 and for Personal Accomplishment is .67 , slightly short of the .70 , thus warranting some caution. Efforts were made to check statistical assumptions such as outliers and skewness. The Depersonalization subscale required a square root transformation to normalize the skewed distribution. A conservative alpha was chosen at .01. Additionally, items were included in the survey to check for construct validity (e.g., the importance of autonomy questions). Factor analyses were run to help increase understanding of construct validity. Likert type response formats were chosen whenever possible over dichotomous formats to help indicate both the strength and direction of the responses. 
Also, the survey was critiqued in advance by several professionals to help identify and correct any ambiguous wording and to check for parallel structure of related survey items.

Survey findings are limited to the sample of psychologists who responded and a response bias is a possibility that could not be assessed in this study. The survey findings are limited to psychologists in the area of the country assessed. Local history during survey distribution time might be a factor influencing psychologists' responses. And, as is always the case in surveys, findings are limited by the veracity and thought given to the responses; socially desirability is a possibility although attempts were made to reduce this bias by making the survey anonymous and uncoded.

Finally, there are other factors that might affect burnout such as difficulty of clients, poor mental health, poor physical health and new interests. Several of these alternative contributors to burnout were assessed by a set of questions in the survey; however, this study is limited by the types of clients that participants see, and other factors that could influence burnout.

\section{Suggestions for Future studies}

This study is intended as a preliminary assessment to gauge the effects of system-wide changes on psychologists' 
autonomy, satisfaction and burnout and to assess psychologists' viewpoints. Further refinement and development of this survey for studies focused on comparison populations of providers (e.g., within clinical psychology: different subspecialties, different populations of patients; providers from other disciplines such as psychiatrists; cross-cultural differences among providers) and for reliability studies is suggested for further research. Given the speed with which such system-wide changes are occurring, continued monitoring of providers' well-being is of interest.

Suggestions for a further lines of study are to test for latent variable structure and to use causal or path analysis to help develop theoretical understanding, not only of the association or relationship between variables such as job autonomy, job satisfaction and burnout, but also for studying patterns of causation among variables.

studies might also follow the pre and post test design, studying attitude change prior to any legislative changes and once again after such changes have been occurred. This was the approach used by Schulz, Scheckler, Girard and Barker (1990) in studying the effect of HMO development.

studies expanding on the autonomy variable in this survey are of interest. The current study used a relatively global measure of autonomy, assessing autonomy in important practice dimensions. Future studies could 
asked more detailed autonomy questions to refine this measure and to see whether results are replicated.

Further studies focusing on provider well-being are of value. Also, studies focusing on value items might lead to understanding of seemingly conflictual findings when measuring personal questions as opposed to questions on the political level.

Locke (1976, pp. 1340-1343) suggests that job satisfaction research should have "logical validity", not just statistical validity. He encourages use of in-depth interviews and longitudinal case studies as a means of increasing our logical understanding of the relationship between important variables.

Studies monitoring the effects of legislation on provider well-being and patient care merit consideration. Additionally, latent political motives for increasing centralization of health care warrant careful monitoring. Ben-Sira's studies (1988) address some of the effects of politization of health care in his book politics and primary medical care: Dehumanization and overutilization. Hayak (1944/1972) the Nobel Memorial Prize winner in Economics (1974), warns of the use of government control over basic needs such as health care as a means, not to improve or extend services, but as a means to subtly consolidate political power over those who become dependent on government. 


\section{APPENDIX}




\section{Definitions}

The following concepts have been defined for the purpose of this study:

Autonomy: The quality or state of being self-governing (Webster's Seventh New Collegiate Dictionary, 1972).

Burnout: "A syndrome of emotional exhaustion and cynicism that occurs among individuals who do 'people work' of some kind" (Udovch, 1983, p. 18). Burnout is characterized by emotional exhaustion, depersonalization (negative, cynical attitudes towards oneself and one's clients) and a diminished sense of personal accomplishment (Maslach \& Jackson, 1986, p.1)

Controls: Restraints and restrictions on provider's freedom of interaction with clients. To directly or indirectly dominate, or maintain command over provider's freedom to practice. (Based on definition of controls in Random House Dictionary, 1968). 
Bureaucracy: An organization with hierarchical levels of authority with power centralized at the top. There is a formally established system of rules and regulations set by the administration. Standards of care generally set by administration, with obligations to the administration taking precedence over the client-patient relationship. payment methods determined by administration. (Engel, 1969, pp. 31-32).

Private practice: A worksetting in which the psychologist is self-employed, either working in a solo practice or with others. (Udovch, 1983, p. 19).

Children: This variable refers to whether the providers have offspring or not. 


\section{BIBLIOGRAPHY}

Aday, I. A. (1989). Designing and conducting health surveys. San Francisco, California: Jossey-Bass.

Ben-Sira, z. (1988). Politics and primary medical care: Dehumanization and overutilization. Vermont: Avebury.

Bertram, D., Hershey, C., Op1la, D. \& Quirin, O. (1990). A measure of physician mental work load in internal medicine ambulatory care clinics. Medical Care 28(5), 458-467.

Bickman, L. \& Dokeck1, P. (1989). Public and private responsibility for mental health services. American psychologist, 44 (8), 1133-1137.

Blank, R. (1988). Rationing Medicine. New York: Columbia University Press.

Blue Cross \& Blue Shield Gallup Poll (1990. July) Second opinions: America's voices and views on health care. (Avallable from 676 North St. Clair St. Chicago, Illinois 60611).

Boy, A. V. \& Pine, G. J. (1980). Avolding counselor burnout through role renewal. Personnel and Guidance Journal. October, 161-163.

Brown, L. D. (1987). Introduction to a decade of transition. In L. D. Brown (Ed.) Health policy in transition: a decade of health politics, policy and law. Durham: Duke University Press.

Bucher, R. \& Stelling, J. (1969). Characteristics of professional organizations. Journal of Health and Social Behavior, 10(1), 3-15.

Buie, J. (1990, January). President signs Medicare bill: victory caps uphill trek. The APA Monitor. p. 17.

Burns, L. R., Andersen, R. M., \& Shortell, S. M. (1990). The effect of hospital control strategies on physician satisfaction and physician-hospital conflict. Health Services Research, 25(3), 527-560.

Califano, J. A. (1986). America's health care revolution. New York: Touchstone.

Cardente, Murphy, Heffner, Remington, Dally, \& Metts (1991). R.I. proposed legislation \#91-H-5010. Avallable from the R.I. State House Document Room. 
CBS This Morning (1990, February 22).

Cherniss, Cary (1980). Professional burnout in human service organizations. New York: Praeger.

Cole, Haynes, Tierney, Tonkin \& Vawter. (Physician panel of speakers). (1989). Medicine: The sick man in a mixed economy. (Cassette Recording). California: Second Renaissance Books.

Colombotos, J. \& Kirchner, C. (1986). Physicians and social change. New York: Oxford University Press.

Conoley, J. C. \& Kramer, J. J. (1989). The tenth mental measurements yearbook. Nebraska: Buros Institute of Mental Measurements.

Cooper, Cary (1977). "Occupational stress", Lecture given to staff of Occupational Health and Safety Groups Naval Medical Region, Long Beach Naval Medical Regional Medical Center, May 16.

Durenberger, D. (1989). Providing mental health care services to Americans. American Psychologist $44(10)$, 1293-1297.

Edelwich, J. \& Brodsky, A. (1980). Burn-out: Stages of disillusionment in the helping professions. New York: Human Services Press.

Engel, G. (1969). The effect of bureaucracy on the professional autonomy of the physician. Journal of Health and Social Behavior 10(1), 30-41.

Freudenberger, H. J. (1974). Staff burn-out. Journal of Social Issues, 30(1), 159-165.

Freudenberger, H. J. (1975). The staff burn-out syndrome in alternative institutions. Psychotherapy: Theory, Research and Practice, $12(1), 73-82$.

Finch, W. A. (1969). Social workers versus bureaucracy. Journal of Health and Social Behavior, 10(1), 370-375.

Freudenberger, H. J. and Richelson, G. (1980). Burn-out: The high cost of high achievement. New York: Anchor Press.

Friedson, E. and Rhea, B. (1963). Processes of control in a company of equals. Social Problems, 11(2), 119-131. 
Gann, M. L. (1979). The role of personality factors and Job characteristics in burnout: A study of social service workers. Unpublished doctoral dissertation, University of California, Berkeley.

Gardner, P., Adams, S., Sherman, C. \& Rainer J. (APA Convention presentation, August 10, 1990) Georgia Psychological Association Survey of Managed Mental Health Programs.

Grumet, Gerald w. (1989). Health care rationing through inconvenience: The third party's secret weapon. The New England Journal of Medicine, 321(9), 607-611.

Hayak, F. A. $(1944 / 1972)$. The road to serfdom. Chicago: University of Chicago Press.

Heckman, S. J. (1980). Effects of work setting theoretical orientation and personality on psychotherapist burnout. Unpublished doctoral dissertation, California School of Professional Psychology, Berkeley, California.

Herrick, r. R. (1989). Medicaid and managed care. In Kongstvedt (Ed.), The Managed Health Care Handbook (ch. 29). Maryland: Aspen.

Jones, R. A. (1985). Research methods in the social and behavioral sciences. Sunderland, Massachusetts: Sinauer Associates.

Joseph, E. D., Devet, C., \& Dehn, T. (1986). The monitoring sourcebook, volume 3: Physician practice monitors. Chicago: Care Communications.

Katzek, R. A. \& Thompson, D. E. (1990, February). Work motivation: Theory and practice. American Psychologist. 45 (2), 144-153.

Kongstvedt, P. (1989). Changing provider behavior in managed care plans. In P. Kongstvedt (Ed.), The Managed Health Care Handbook (ch. 9). Maryland: Aspen.

Ku, L. \& Fisher, D. (1990). The attitudes of physicians toward health care cost-containment policles. Health Services Research. 25(1), 25-42.

Leese, S. (1990, October). Psychiatrists: "Don't look behind you? Someone may be catching up!". American Journal of Psychotherapy. XLIV (4), 467-470.

Leyerle, B. (1984). Moving and shaking American medicine: The structure of a socioeconomic transformation. Westport, Connecticut: Greenwood Press. 
Licthenstein, R. (1984). The job satisfaction and retention of physicians in organized settings: A literature review. Medical Care Review, 41(3), 139-179.

Locke, E. A. (1976). The nature and causes of job satisfaction. In M. D. Dunette (Ed.), Handbook of Industrial and Organizational Psychology (pp. 297-1349). Chicago: Rand McNally College Publishing Company.

Locke, E. A. \& Schweiger, D. M. (1979). Particlpation in Decision-Making: One more look. Research in Organizational Behavior, 1, 265-339.

Locke, E. A. \& Latham, G. (1984). Goal setting: A motivational technique that works!. New Jersey: Prentice-Hall.

Lorentzen, K. \& Roemer, L. (1988). Health services administration: Education and practice. Missouri: warren H. Green, Inc.

Mangano, C. (Author and Producer), Mayo, K. (Editor) Freudenberger, H. (Consultant). (1982). Burnout on the job. [Video and accompanying teachers guide]. New York: Human Relations Media.

Maslach, C. (1976). Burned-out. Human Behavior, $\underline{\mathbf{5}}(9)$, 16-22.

Maslach, C. (1982). Burnout: The cost of caring. New Jersey: Prentice Hall.

Maslach, C. \& Jackson, S. (1985). The role of sex and family variables in burnout. Sex Roles, 12(7/8), $837-851$.

Maslach, C. \& Jackson, S. (1986). Human Services Survey. Palo Alto: Consulting Psychologists.

Mechanic, D. (1972). General medical practice: Some comparisons between the work of primary care physicians in the United States and England and wales. Medical Care, $\underline{x}(5), 402-420$.

Michaels, J. (1987). Understanding the legal issues. In Hospital-sponsored Health Maintenance organizations (ch. 4). American Hospital Publishing.

McDowell, I. \& Newell, C. (1987). Measuring health: A quide to rating scales and questionnaires. New York: Oxford University Press. 
McGihon, C., Kuebbing, S., Adams, A., Adams, M., Foster, K. \& Briddell, D. (1990, August). The Group Independent Practitioner Model: An alternative to managed health care. Symposium conducted at the 98th American Psychological Convention, Boston.

Medeiros, M. \& Prochaska, J. (1988). Coping strategies that psychotherapists use in working with stressful clients. professional Psychology Research and Practice 19(1), 112-114.

Meichenbaum, D. (1985). Stress inoculation training. New York: Pergamon Press.

Moldawsky, S. (1990). Is solo practice really dead?. American Psychologist 45(4), 544-546.

Muchinsky, P. (1987). Psychology applied to work: Introduction to Industrial and organizational Psychology. (2nd ed.) Chicago: Dorsey Press.

Norusis, M. (1988). SPSS-X Introductory statistics quide. Chicago: SPSS Inc.

Perkey, B. (1989). Public and private responsibility for mental health services. American Psychologist $44(8)$, 1148-1150.

Pines A. \& Aronson, E. (1988). Career burnout: Causes and cures. New York: The Free Press.

Prybil, L. (1971). Physician terminations in large multispecialty groups. Part II: factors that influence physicians to leave multispecialty group practice. Medical Group Management, $18(6), 4-6,24-25$.

Random House dictionary of the English language (1968). New York: Random House.

Ross, A. (1969). A report on physician termination in group practice. Medical Group Management, 16, 15-21.

Rutman (1984). Evaluation research methods: A basic guide (2nd ed.). Beverly Hills, California: SAGE Publications.

Schlotzhauer, S. D. \& Littell, R. C. (1987). SAS System for elementary statistical analysis. Cary, North Carolina: SAS Institute.

Schoenbaum, S. C. \& Plotkin, G. R. (1989). Making the transition from quality assurance to quality improvement. HMO Practice, 3(5), 161-163. 
Schulz, R., Scheckler, w. M., Girard, C. \& Barker, K. (1990). Physician adaptation to Health Maintenance Organizations and implications for management. Health Services Research 25(1), 43-63.

Schulz, R. \& Schulz, C. (1988). Management practices, physician autonomy, and satisfaction. Medical Care $\underline{26}(8), 750-763$.

Selye, H. (1956). The stress of life. New York: McGraw-Hill.

Selye, H. (1974). Stress without distress. New York: Lippincott.

Simons, L. (1989). Privatization and the mental health system. American Psychologist 44(8), 1138-1141.

Spies, J. Friedland, J. \& Fox, P. (1984). Alternative health care delivery systems: HMO's and PPO's. In P. Fox, W. Goldbeck \& J. Spies (Eds.), Health care cost management: Private sector initiatives (ch. 3 ). Michigan: Health Administration Press.

Steiner, T. (1980). Burnout prevention. Unpublished manuscript.

Stern, L. (1990). The future of private practice. Family Therapy Networker, 14(6), pp.54-57, p. 65 .

Tabachnick, B. \& Fidell, L. (1983). Using multivariate statistics. New York: Harper and Row.

Taylor, M. G. (1990). Insuring national health care: The Canadian experience. N. Carolina: University of $\mathrm{N}$. Carolina Press.

Toner, R. (1988, April 22). Health insurance and political hoopla. New York Times.

Udovch, S. L. (1983). The effects of work environment and personality in burnout: A study of psychologists. Unpublished doctoral dissertation, United States International University.

Wagner, E. (1989). Types of managed health care organizations. In P. Kongstvedt (Ed.), The managed health care handbook (ch. 2). Maryland: Aspen.

Warnath, C. \& Shelton, J. (1976). The ultimate disappointment: The burned-out counselor. Personnel and Guidance Journal, 55, 172-175. 
Webster's seventh new collegiate dictionary (1972). Springfield, Massachusetts: Merriam.

The new Webster's dictionary (1990). New York: Lexicon Publications.

Weiss, B. Senf, J. (1990). Patient satisfaction survey instrument for use in health maintenance organizations. Medical Care 28(5), 434-445. 